\title{
Queimar ou não queimar? Um estudo de caso da roça sem queima na comunidade
}

\section{São Sebastião do Livramento-Cutias/AP}

To burn or not to burn? A case study of the unburned farm in the community of São Sebastião do

Livramento-Cutias/AP

¿Quemar o no quemar? Un estudio de caso de la finca sin quemar en la comunidad de São

Sebastião do Livramento-Cutias/AP

\section{Resumo}

Com o objetivo de investigar o uso do fogo em comunidade rural no Amapá, caracterizando os modelos produtivos, dos agricultores familiares alternativos, compreendendo como constroem uma mudança no modelo de produção, bem como reproduzem seus conhecimentos empíricos. Foram avaliadas propriedades agrícolas entre Agosto e Setembro de 2019. O estudo teve como estratégia a "pesquisa exploratória", realizada através de questionário com 20 agricultores. Os dados obtidos foram tabulados, analisados e agrupados com Microsoft Excel 2010® e filtro Minitab. O sistema de derruba e queima ainda adotada. A mudança das práticas dos agricultores sobre o uso do solo, vem sendo modificada paulatinamente. A opção pelo uso do fogo está relacionada com redução de custos na limpeza da área produtiva. Dos $85 \%$ dos agricultores entrevistados informaram que não utilizam o fogo como técnica de limpeza, contudo dados estes divergem das informações obtidas através de imagem de satélites. A cultura da mandioca desponta como uma das 
principais. Os agricultores (90\%) conhecem as vantagens das cinzas para as plantas e o solo. Quanto a desvantagem do do fogo (55\%) dizem ter conhecimento, contudo observou-se, que desconhecem a Legislação. Técnicas para evitar desmatamentos e queimadas como: utilização da mesma área por destoca, aração e gradagem, além de cuidados como a conservação de solos, efetuando rotação de cultivos com leguminosas, plantio direto e variedades mais produtivas, foram também observadas. É necessário que políticas públicas sejam implementadas, objetivando reduzir o custo de recuperação da área com práticas sustentáveis e mais baratas.

Palavras-chave: Agricultura familiar; Fogo; Manejo agrícola.

\begin{abstract}
With the aim of investigating the use of fire in rural community in Amapá, characterizing the productive models, of alternative family farmers, understanding how they construct a change in the production model, as well as reproduce their empirical knowledge. Agricultural properties were assessed between August and September 2019. The study had as strategy the "exploratory research," carried out through questionnaire with 20 farmers. The data obtained was tabulated, analyzed and grouped with Microsoft Excel 2010 ® and Minitab filter. The system of overthrow and burning still adopted. The change in farmer practices on land use has been gradually changed. The option for fire use is related to cost reduction in cleaning the productive area. Of the $85 \%$ of farmers surveyed, they reported that they do not use fire as a cleaning technique, but data differ from information obtained through satellite imaging. The culture of cassava is one of the main ones. Farmers (90\%) know the advantages of ash for plants and soil. As for the disadvantage of fire $(55 \%)$ say they have knowledge, however it was observed, that they do not know the Legislation. Techniques to avoid deforestation and burns such as: use of the same area by stew, ploughing and grading, in addition to care such as soil conservation, rotating crops with legumes, direct planting and more productive varieties, were also observed. It is necessary that public policies be implemented, aiming to reduce the cost of recovery of the area with sustainable and cheaper practices.
\end{abstract}

Keywords: Agricultural management; Family farming; Fire.

\title{
Resumen
}

Con el objetivo de investigar el uso del fuego en la comunidad rural de Amapá, caracterizar los modelos productivos, de agricultores familiares alternativos, entender cómo construyen un cambio en el modelo productivo, así como reproducir sus conocimientos empíricos. Las propiedades agrícolas fueron evaluadas entre agosto y septiembre de 2019. El estudio tuvo como estrategia la «investigación exploratoria», realizada a través de cuestionario con 20 agricultores. Los datos obtenidos fueron tabulados, analizados y agrupados con filtro Microsoft Excel 2010 ® y Minitab. El sistema de derrocamiento y quema sigue siendo adoptado. El cambio en las prácticas de los agricultores sobre el uso de la tierra se ha modificado gradualmente. La opción para el uso de incendios está relacionada con la reducción de costos en la limpieza del área productiva. Del $85 \%$ de los agricultores encuestados, informaron que no utilizan el fuego como técnica de limpieza, pero los datos difieren de la información obtenida a través de imágenes satelitales. La cultura de la yuca es una de las principales. Los agricultores $(90 \%)$ conocen las ventajas de la ceniza para las plantas y el suelo. En cuanto a la desventaja del fuego (55\%) dicen tener conocimiento, sin embargo se observó, de que no conocen la Legislación. También se observaron técnicas para evitar la deforestación y quemaduras como: uso de la misma zona por estofado, arado y clasificación, además de cuidados como conservación del suelo, cultivos rotatorios con legumbres, siembra directa y variedades más productivas. Es necesario que se implementen políticas públicas, con el objetivo de reducir el costo de recuperación de la zona con prácticas sostenibles y más baratas.

Palabras clave: Agricultura familiar; Fuego; Manejo agrícola.

\section{Introdução}

O Projeto de pesquisa surge apartir da necessidade de pensar no agroecossistema de forma sustentável, e través de uma perspectiva de totalidade, oportunizando ao estudante a capacidade de compreender esse processo nas suas formas de produção de maneira transversal, multidisciplinas e interdisciplinar.

A opção pela interdisciplinaridade implica a necessidade de superar a visão fragmentada na produção do conhecimento, recuperando a ideia de unidade, de síntese, do todo e de integração dos saberes. Essa interação, entre diferentes disciplinas, possibilita a construção de um saber crítico-criativo-reflexivo, a ser valorizado no processo de ensino-aprendizagem. Nessa perspectiva, a interdisciplinaridade surge para superar a fragmentação existente inter e intradisciplinar, possibilitando um diálogo entre elas e relacionando-as entre si para melhor compreender a realidade e, assim, desenvolver maior capacidade de enfrentar um problema maior - que se trata de como produzir mais e melhor os alimentos para uma vida mais saudável (Oliveira, 2013).

Assim, a elaboração de uma proposta de ensino, através da metodologia de projetos, busca a compreensão de uma unidade de produção agrícola familiar e pressupõe um planejamento inserido em um contexto economicamente viável, 
socialmente justo e ambientalmente adequado. De acordo com Casalinho e Cunha (2016), isso implica na integração das disciplinas que compõem os semestres da estrutura curricular do curso de agronomia. Trata-se de uma atitude interdisciplinar que intenta a formação de um profissional capaz de compreender essa forma de pensar, na perspectiva da totalidade.

A proposta do Projeto surge apartir da demanda de docentes e discentes, na tentativa de construir uma proposta práticapedagógica que pudesse orientar para uma formação acadêmica comprometida com as novas demandas da sociedade, baseada para o egresso de um profissional que atue na construção de um desenvolvimento rural sustentável. Desta forma objetivou-se analisar o conjunto de técnicas alternativas ao uso do fogo utilizadas por agricultores familiares da comunidade São Sebastião do Livramento, por meio de metodologia e métodos que despontem com objetivos coerentes e atualizados, bem mais próximos da realidade, contemplando, inclusive, a preocupação ambiental.

\section{Material e Métodos}

\section{1 Área de estudo}

Para a obtenção dos dados requeridos pela pesquisa, foram avaliadas propriedades agrícolas, previamente identificadas, através de visitas in loco e apontadas pelo presidente da Associação Agropecuária da Comunidade de São Sebastião do Livramento (AGROPES).

A área de estudo delimitada está localizada no Município de Cutias do Araguarí no estado do Amapá na comunidade São Sebastião do Livramento sob Coordenadas geográficas: $0^{\circ}, 59^{\prime}$ e 4" de latitude e $50^{\circ}, 48^{\prime}$ e $10^{\prime \prime}$ de longitude.

Figura 1. Comunidade São Sebastião do Livramento, Amapá, Brasil.

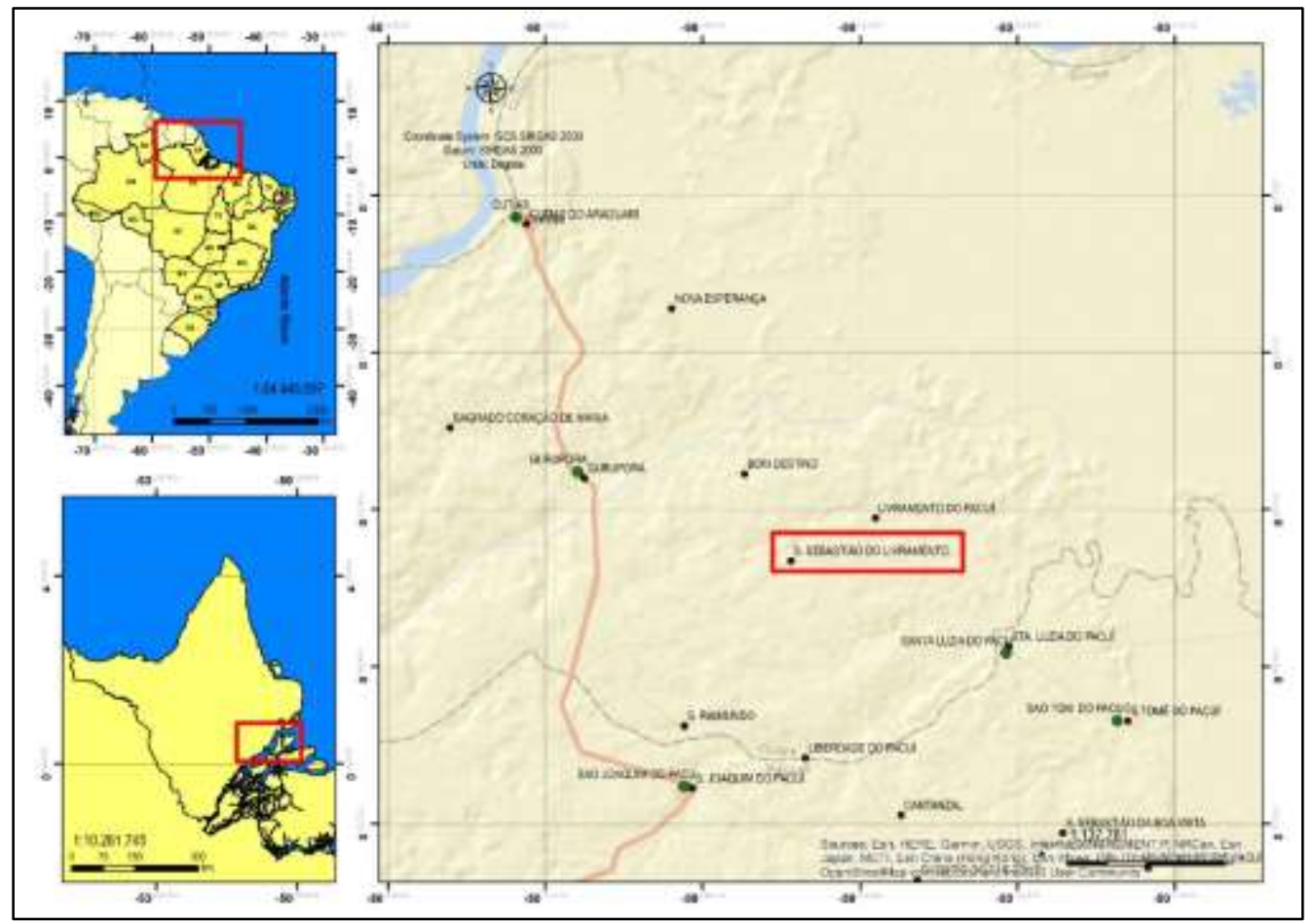

Fonte: Autores (2021).

Vale ressaltar que este local foi o foco do estudo, pois apresentou características relevantes, tais como:

1-Possuem experiências apontadas e identificadas no processo de transição ao uso do fogo para sistemas mais sustentáveis; 2-Está entre os principais fornecedores para as feiras dos produtores em Macapá. 3-Possuem experiências agrícolas que vêm sendo identificadas pelo órgão de extensão oficial do Estado. 


\subsection{Método utilizado}

A pesquisa ocorreu com agricultores da Comunidade de São Sebastião do Livramento no município de Cutias/AP. As visitas ocorreram nos períodos de agosto e setembro de 2019. A pesquisa apresentou natureza qualitativa e quantitativa tendo como estratégia de "pesquisa exploratória", realizada através de questionário base, observação in loco e aplicação de um questionário semi-estruturado, segundo a metodologia adaptada de Souto et al. (2011). O questionário será voltado a conhecer, com mais detalhes, as práticas adotadas pelos agricultores familiares entrevistados quanto ao uso do fogo.

\subsection{Análises dos dados}

Os dados empíricos obtidos através das entrevistas foram distribuídos em valores percentuais, tabulados, analisados e agrupados com auxílio da planilha eletrônica Microsoft Excel 2010® e um filtro de dados (Minitab). E a interpretação dos dados seguiu o indicado em análise de conteúdo de Bardin (2009) sendo que foi seguido o seguinte ordenamento: (1) pré-análise, em que o material foi organizado por meio de leitura flutuante; (2) elaboração de indicadores para a interpretação; (3) codificação dos dados a partir das coesões dos fatos; (d) categorização segundo os padrões de respostas.

\section{Resultados e Discussões}

A mudança das práticas adotadas pelos agricultores sobre o uso do solo, vem sendo modificada, mesmo que timidamente. O sistema de derruba e queima ainda é a principal prática adotada, algumas mudanças ou processos de transições foram observadas in loco no decorrer das visitas. A pesquisa foi realizada com um quantitativo de 20 agricultores, escolhidos e apontados pelo Presidente da Associação, que foi peça fundamental para a realização do trabalho de campo. Durante a pesquisa procurou-se, de forma discreta, observar, quando possível, se as informações quanto ao não uso do fogo era verdadeira, pois pôde-se obervar, em algumas situações, que o agricultor tinha receio em informar que ainda utilizava a prática do uso do fogo, mesmo para limpeza da área. Na sequência discutiremos sobre as perguntas levantadas aos agricultores.

\subsection{Caracterização do sistema de produção}

Como já apontado por Salais (1996), na década de 90 já poderíamos caracterizar como sistema produtivo local como uma forma de organização econômica eficaz e, além disso, como espaço que abriga processos econômicos e coletivos. E assim, foi possível observar que na localidade em questão apesar dor produtores definirem seu carro chefe eles procuram diversificar seus sistemas produtivos com a introdução de espécies com ciclos diferenciados. Quanto o que produzem em suas propriedades iremos discutir na Figura 2 abaixo apresentado. Nele podemos observar como os agricultores conseguem se reproduzir economicamente. 
Research, Society and Development, v. 10, n. 16, e155101622537, 2021

(CC BY 4.0) | ISSN 2525-3409 | DOI: http://dx.doi.org/10.33448/rsd-v10i16.22537

Figura 2 - O que é produzido na propriedade.

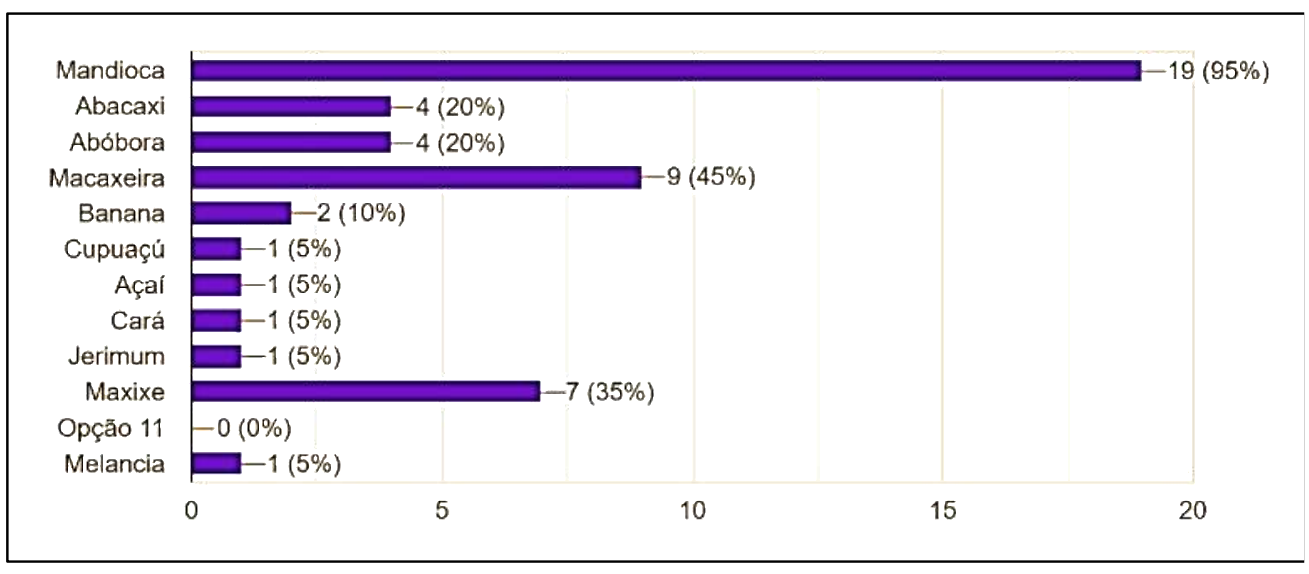

Fonte: Autores (2021).

Dos 20 (vinte) agricultores entrevistados 19 (dezenove), ou seja, 95\% afirmam que plantam e vendem a cultura da mandioca seguidos pelo abacaxi, abóbora, Macaxeira, banana, Cupuaçú, Açaí, Cará, Jerimum, Maxixe, melancia, dentre outras de menores expressão.

Dentre as 11 culturas informados pelos agricultores, identificou-se que eles elegeram como "carro chefe" (principal produto comercializado) a mandioca (ver Figura 3), produto este que desponta na região como uma das principais fontes alimentares.

Figura 3 - Área do plantio de mandioca na Comunidade São Sebastião do Livramento.

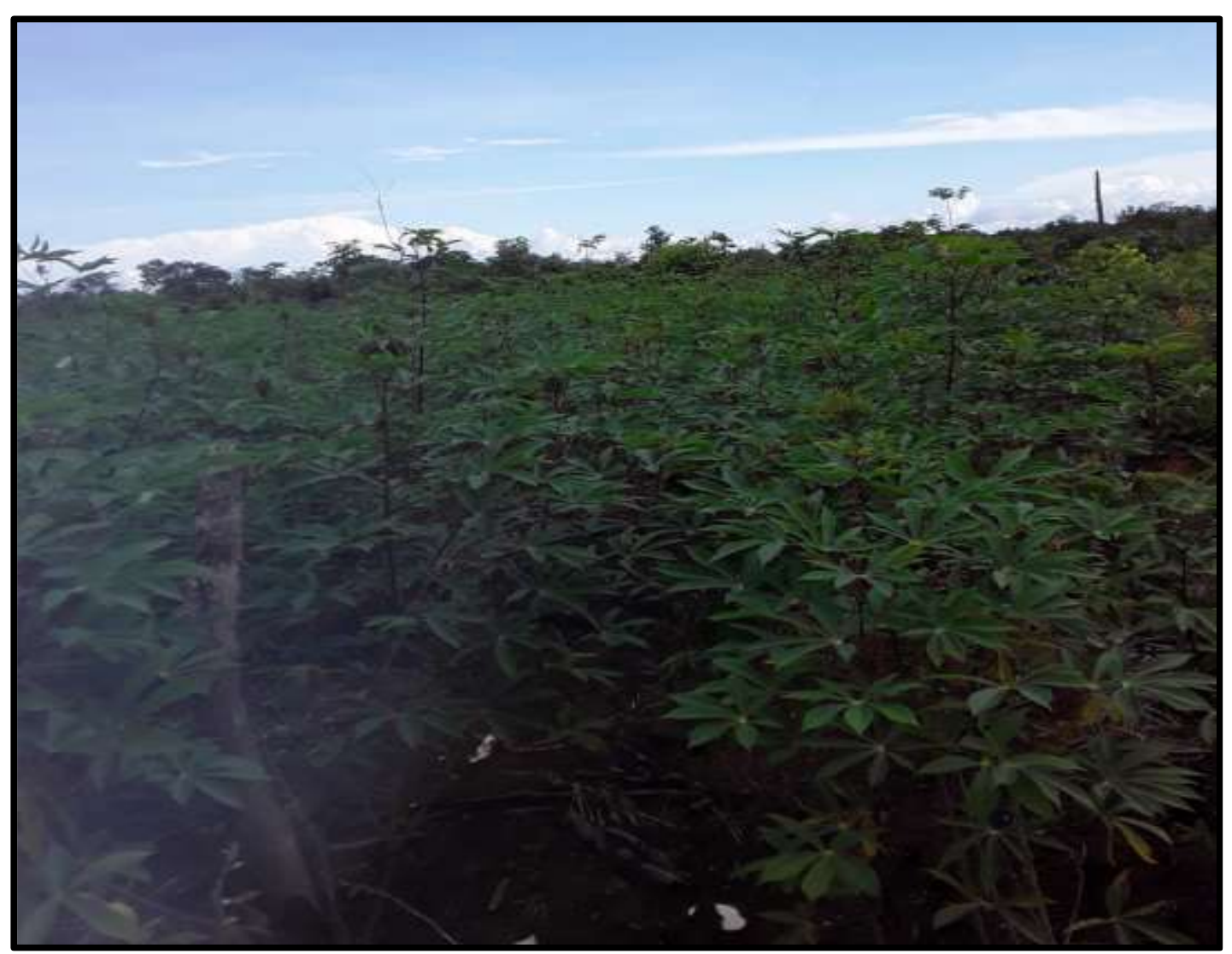

Fonte: Autores (2021). 
A mandioca se apresenta como opção para garantir a qualidade de vida das comunidades tradicionais na Amazônia, além de reduzir o fluxo migratório do homem do campo para os grandes centros urbanos, já sinalizado por Richetti, (2007) e Balsan, (2006).

Para os autores Silva, Rodrigues e Palheta (2014), a cadeia produtiva de mandioca ainda desponta como um mercado voltado ao abastecido regional mostrando-se com grande capacidade de expansão na região Norte do Brasil. Para o RURAP (2015), A mandioca é o principal produto da agricultura familiar no Amapá, e constitui a principal fonte de alimentação e de renda dos pequenos agricultores sendo responsável por produzir $14.421,557 \mathrm{~kg}$ de farinha que abastece o mercado local, considerado o mais importante complemento alimentar.

Assim, tendo em vista o que foi observado "in loco", a adoção de medidas que visem o melhoramento do nível tecnológico e de assistência técnica, voltados à cadeia produtiva, poderá oportunizar que agricultores consigam agregar valor ao produto "in natura" e seus derivados, gerando desenvolvimento econômico local e melhorando a condição social das famílias envolvidas no processo de produção.

A Figura 4 apresenta informações quanto a área utilizada pelos agricultores para o plantio das culturas informadas, nele podemos observar que a maior parte dos entrevistados, $60 \%$ (sessenta porcento) utilizam as 4 tarefas para conseguirem alcançar a produtividade desejada.

Figura 4 - Área utilizada para plantio.

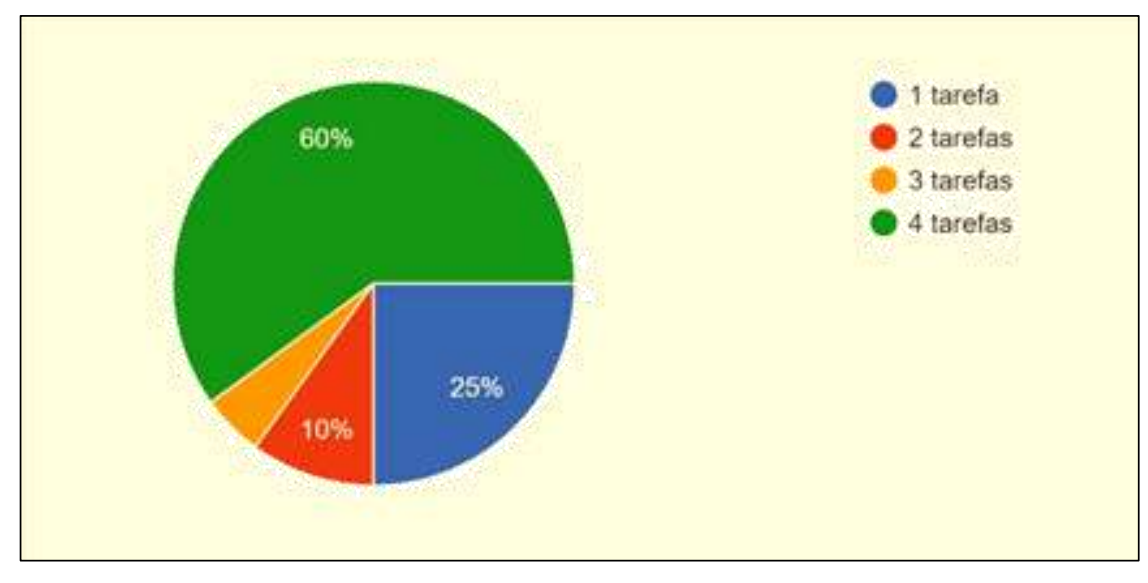

Fonte: Autores (2021).

De acordo com Kageyama, Bergamasco e Oliveira (2013), a agricultura de base familiar se apresenta em mais de 90\% dos estabelecimentos chegando a ocupar $60 \%$ da área total recenseada de acordo com os levantamentos realizados pelos autores naquele ano, fato este também encontrado nesta pesquisa onde $60 \%$ dos agricultores utilizam 4 tarefas, ou seja, $100 \mathrm{~m}^{2}$ de área plantada. Segundo informações obtidas através do RURAP (2015) o agricultor familiar do Estado do Amapá possui lotes que variam de 50ha a 70ha, destes precisam deixar 20\% para área de reserva ou de recomposição florestal.

O Censo Agropecuário de 2006 registrou ainda 12,3 milhões de pessoas trabalhando na agricultura familiar (74,4\% do pessoal ocupado no total dos estabelecimentos agropecuários). Conforme o Instituto Brasileiro de Geografia e Estatística - IBGE, no Censo Agropecuário de 2006, foram identificados 4.367.902 estabelecimentos de agricultura familiar. E ainda, apesar de cultivar uma área média de lavouras significativamente pequena comparada com a agricultura não familiar - apenas 18,37 hectares contra 309,18 hectares - a agricultura familiar é a principal fornecedora de alimentos básicos para a população brasileira: abastece $87 \%$ do consumo nacional da mandioca, $70 \%$ do feijão, $46 \%$ do milho, $38 \%$ do café e $34 \%$ do arroz.

Quanto ao sistema de irrigação adotado pelos agricultores $95 \%$ informaram que não possuem um sistema automatização e utilizam a irrigação manual. O mesmo poço também é utilizado para irrigação das culturas (95\%) e 100\% utilizam água de 
poço para consumo doméstico, o que está apresentado nas Figuras 5, 6 e 7.

Figura 5 - Origem da água para a irrigação.

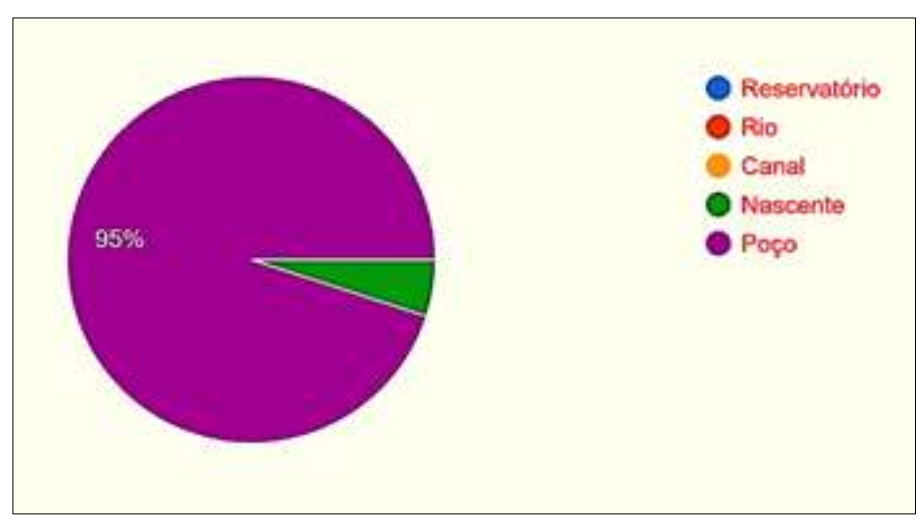

Fonte: Autores (2021).

Figura 6 - Uso do sistema de irrigação.

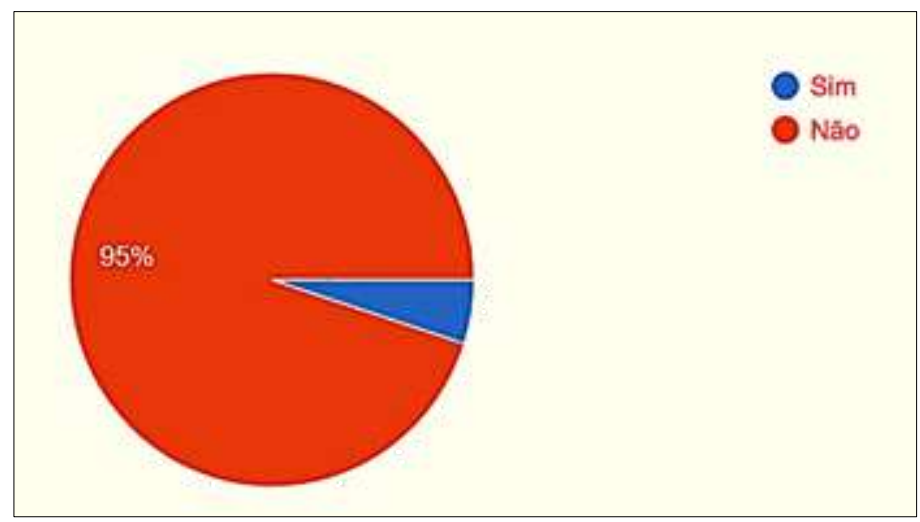

Fonte: Autores (2021).

Figura 7 - Origem da água para consumo.

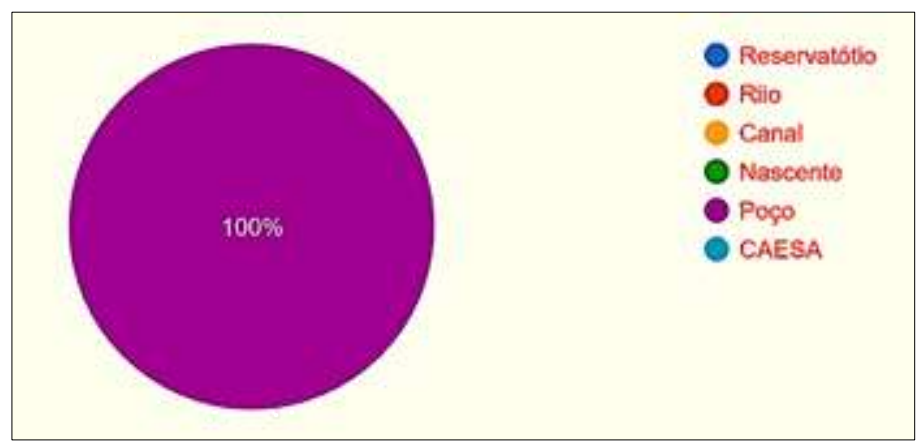

Fonte: Autores (2021).

A irrigação de culturas agrícolas é uma prática utilizada para complementar a disponibilidade da água provida naturalmente pela chuva, proporcionando ao solo teor de umidade suficiente para suprir as necessidades hídricas das culturas. A irrigação a nível de agricultura familiar no Brasil, de acordo com Coelho et al. (2015), tem sido limitada, principalmente polo custo inicial de instalação de sistemas de irrigação para o pequeno produtor afastando-o de tecnologias que poderiam contribuir economicamente na sua produção. $\mathrm{O}$ que foi sinalizado pelos agricultores no trabalho de campo foi que, o acesso a sistemas de irrigação torna-se inviável pelo alto custo de investimento sendo este o principal fator limitante que afasta os mesmo de 
tecnologias importantes que poderiam contribuir significativamente na economia de sua propriedade.

É recomendável que poderes públicos proponham ações que viabilizem acesso destas tecnologias para os pequenos agricultores ou também intitulados de agricultores familiares, tendo em vistas que os mesmos são um dos principais incentivadores da produtividade local.

Como já afirmado por Testezlaf (2017) a irrigação é tida como tecnologia imprescindível no processo de aumento da produção de bens agrícolas e no desenvolvimento humano.

Quanto a água utilizada para o sistema de irrigação e para o abastecimento de sua propriedade, mais de 90\% dos agricultores informaram optar por utilizar água de poço mesmo sendo abastecido pela Companhia de abastecimento de água. Pra eles a água do poço é muito mais limpa e sem gosto enquanto que a água fornecida pelo sistema de abastecimento do município é "suja" e com gosto de ferrugem.

Sandri e Rosa (2017) relatam que o setor agrícola é responsável por 87\% do consumo total de água de boa qualidade no mundo, destinada principalmente à irrigação de grandes áreas frutíferas, culturas anuais e horticultura. Para Queiroz et al. (2016), a água é um recursos fundamental para a produção de alimentos e seu uso deve ser realizado de forma racional e qualitativa na irrigação.

É de conhecimento que grande parte da reserva de água doce do planeta não é disponibilizada em forma potável, estudos realizados por Costa et al. (2012) apresentam resultados onde, na maioria das vezes, águas provenientes de poços, são menos comprometidas por fatores físico-químicos e biológicos, do que os mananciais superficiais, porém, a preocupação vem aumentando pois as formas de utilização dessas águas estão elevando-se então, cabe salientar sobre a importância de verificar a sua qualidade desta água.

No Brasil, as legislações vigentes que tratam de potabilidade da água para consumo humano e de águas subterrâneas são, respectivamente, a Portaria no 2914, de 12 de dezembro de 2011, do Ministério da Saúde (Brasil, 2011) e a Resolução $n^{\circ}$ 396, de 3 de abril de 2008, do Conselho Nacional do Meio Ambiente (CONAMA).

A Figura 8 apresenta dados referente a utilização de corretivos pelos agricultores. Dos 20 agricultores entrevistados 80\% informaram que não utilizam corretivos químico síntéticos no solo para corrigir a acidez.

Figura 8 - Uso de corretivos nos solos.

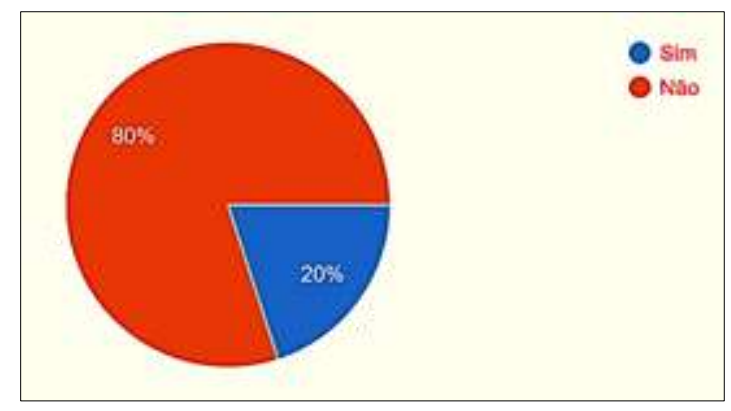

Fonte: Autores (2021).

Por questões geológicas, os solos brasileiros tendem a ser mais ácidos, ou seja, apresentam maior quantidade de íons, principalmente o hidrogênio $(\mathrm{H})$, que nem sempre são ideais para o desenvolvimento de uma determinada cultura e o uso de corretivos no solo é importante pois contribui para equilibrar os nutrientes dos solos e aumenta a produtividade do plantio. Levantamentos realizados pela Embrapa-AP por Melém Júnior et al. (2008) já nos apresentava um diagnóstico da região de estudo. Nele os pesquisadores apresentam de forma geral as análises da fertilidade dos solos de 4 grupos de regiões, assim intitulada por eles, para melhor apresentarem as variáveis estudas. 
Sobre a análise dos componentes principais (ACP) o município de Cutias do Araguarí, região onde está localizada a Comunidade de São Sebastião do Livramento, a análise dos dados apresentada informa que a região apresenta elevada acidez e elevado teor de alumínio trocável, baixos teores de fósforo e soma de bases, baixa saturação por bases e médios teores de carbono. Esses dados sinalizam que essa região necessita de corretivos por apresentarem elevada acidez. Como justificativa ao não uso de corretivos os agricultores informaram que o custo elevado para investimento em adubos sintéticos e calcário não compesaria o retorno financeiro, outra opção é a utilização de corretivos e fertilizantes. Contudo, como informado na pequisa anterior, a opção em não realizar a correção dos solos resulta da diminuição da produtividade, veja no Tabela 1 a seguir:

Tabela 1 - Rendimento das lavouras temporárias por grupo de municípios.

\begin{tabular}{ccccc}
\hline Grupos & Arroz & Feijão & Mandioca & Milho \\
\hline & \multicolumn{5}{c}{$\mathrm{kg} \mathrm{ha}^{-1}$} \\
\cline { 2 - 5 } 1 & 801 & 543 & 9924 & 817 \\
2 & 945 & 680 & 11124 & 853 \\
3 & 740 & 596 & 10886 & 851 \\
4 & 806 & 674 & 10730 & 838 \\
\hline
\end{tabular}

*Grupo 1: Cutias e Mazagão; Grupo 2: Calçoene, Itaubal, Porto Grande, Pracuúba e Tartarugalzinho; Grupo 3: Laranjal do Jarí, Macapá, Pedra Branca, Santana e Serra do Navio e Grupo 4: Amapá, Ferreira Gomes, Oiapoque e Vitória do Jarí. Fonte: IBGE (2005).

Ao analisarmos a Tabela 1, podemos observar que o Município de Cutias é o que se apresenta com menor produtividade, fato este que pode estar intimamente relacionado aos fatores de fertilidade dos solos e sua correção.

Outras informações referente aos aspectos pedológicos da localidade confirmam a acidez responsável pela baixa produtividade local, informações estas presentes no documento de subsídio ao Zoneamento Ecológico- -Econômico (ZEE) entregue por Venturieri (2017).

\subsection{Caracterização das práticas de limpeza dos resíduos}

Sobre a coleta seletiva e o qual destino final o agricultor realizava, $70 \%$ informaram que na comunidade existe os sistemas de coleta seletiva, o que foi demonstrado no Figura 9. Mesmo com a coleta seletiva realizada alguns agricultores, $30 \%$ informaram queimar o lixo, segundo eles assim acreditam ser uma forma mais rápida e célere de reduzir animais peçonhentos e roedores facilitando dessa forma o não acúmulo.

Figura 9 - Coleta do lixo doméstico.

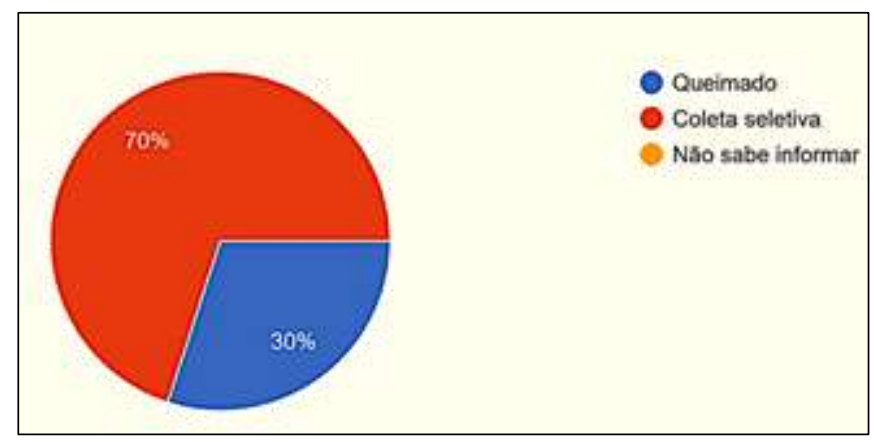

Fonte: Autores (2021).

A problemática da gestão de resíduos sólidos domiciliares é uma crescente preocupação de municípios por todo o país, 
sendo estudada com maior interesse nas últimas décadas. De acordo com dados apresentados pela WWF (2019) o Brasil é o quarto maior produtor de resíduos plásticos do mundo, produzindo 11 milhões de toneladas por ano. A Política Nacional de Resíduos Sólidos (Lei n ${ }^{12.305 / 10)}$ prevê que deve haver a redução na geração de lixo, assim como a prevenção de sua produção.

De acordo com Rocha (2013), na região rural, há uma grande negligência quanto à destinação correta do lixo, as concepções equivocadas sobre o lixo produzido na zona rural e a negligência são muito prejudiciais no sentido de afetar diretamente a eficiência nos sistemas de coleta rural, eficiência esta que pode ser questionada apenas caso existam tais sistemas, que de fato raramente existem. Assim em áreas rurais, o uso de formas alternativas de se livrar do lixo, como queimadas, acaba, portanto, frequentemente empregado nestas áreas, algo que pode ser atribuído justamente a esta ineficiência, esta fato já apontado por Kazubek (2010), Ceretta et al. (2013).

Ainda sobre esses autores a utilização de "recursos" como queimadas e soterramentos de resíduos caracterizam impactos negativos diretos ao ambiente, como danos ao solo, além de danos que não são levados em consideração pelo potencial em afetar a qualidade de vida e poluir os lençóis freáticos, influenciando na qualidade da água.

Assim, é importante se voltar a atenção do poder público para estas localidades com o objetivo de atender a Lei 12.305/10, que trata da responsabilidade compartilhada pela população, poder público, empresas etc.

Nas figuras abaixo (Figura 10 e 12) seguem as informações quanto a limpeza de sua propriedade e o destino desse resíduo. $100 \%$ afirmam realizar a capina manual, por se tratar de pequenas áreas eles informam que conseguem realizar a atividade manualmente, contudo, esporadicamente o fazem utilizando a capina mecânica (mecanizada) (5\%). Nenhum agricultor informou utilizar os herbicidas ou o fogo para auxiliar na limpeza da área.

Figura 10 - Como realiza a limpeza na área da produção.

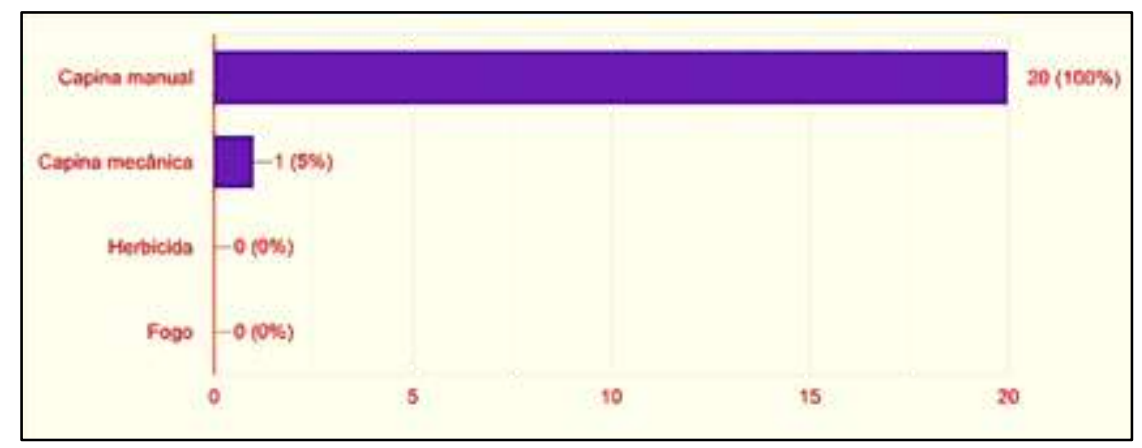

Fonte: Autores (2021).

O controle plantas invasoras é realizado por meio de práticas de eliminação do mato, como o arranquio manual, a capina manual, a roçada e o cultivo mecanizado feito por cultivadores tracionados por animais ou trator, a monda ou arranquio manual é o método mais antigo de controle de plantas daninha (Gomes \& Leal, 2003), o que também foi confirmado nessa pesquisa.

O uso de herbicidas é uma das práticas mais apontadas como efetiva no controle da rebrota de espécies invasoras, a capina mecânica enfraquece a fertilidade dos solos bem como não impede que as espécies brotem ou rebrotem, pelo contrário ajuda na disseminação dessas espécies, fala esta dita pelo consultor Pires (2020): “a capina com o uso de enxada é um controle temporário, serve para determinada época, depois voltam. Existem algumas plantas que, se você roçar periodicamente, quanto mais roçar vai 'engrossando' embaixo da terra, o que acaba dificultando sua eliminação definitiva” (PIRES, 2020).

O fato das práticas de limpeza ocorre de forma manual nas propriedades também está relacionada com o custo do valor investido para utilizar maquinário ou herbicidas. 5\% dos agricultores informam que o acesso a políticas públicas, órgão de extensão são deficientes, existe, contudo, não há uma continuidade. O uso de maquinários ocorre quando ha uma ação específica dos órgãos que atuam tanto com a extensão quanto com o órgãos que atuam no desenvolvimento rural do município e, em 
algumas situações são disponibilizados para a comunidade também atarvés da Associação ou Cooperativa (ver Figura 11).

Figura 11 - Área destinada à mecanização na Comunidade São Sebastião do Livramento.

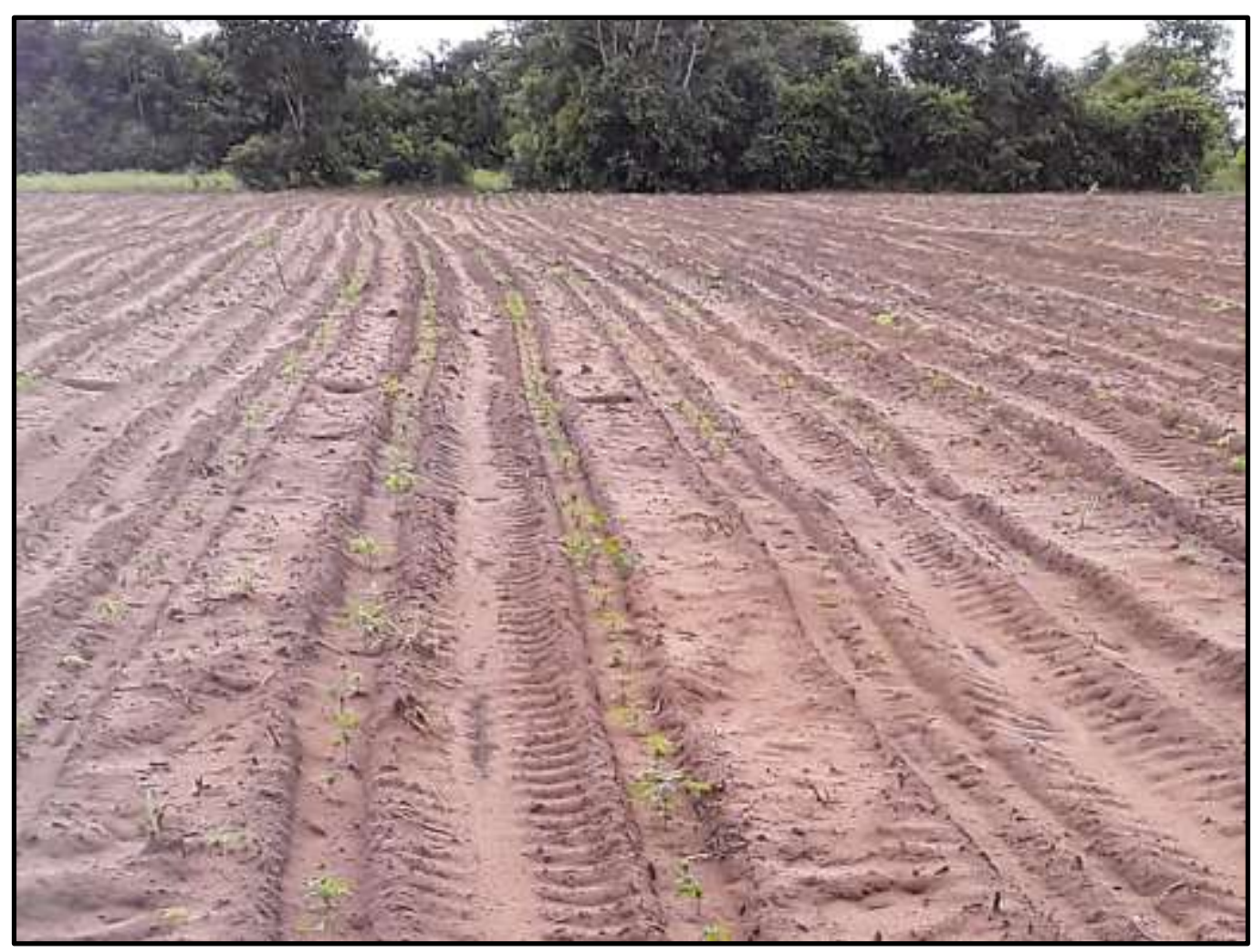

Fonte: Autores (2021).

Quanto ao destino desses resíduos, apresentado no Figura 12, dos 20 agricultores entrevistados 95\% informam utilizar esse resíduo para o preparo de composto para adubação orgânica e 60\% utilizam também como complemento na alimentação animal.

Figura 12 - Destino dado ao resíduo da limpeza na área da produção.

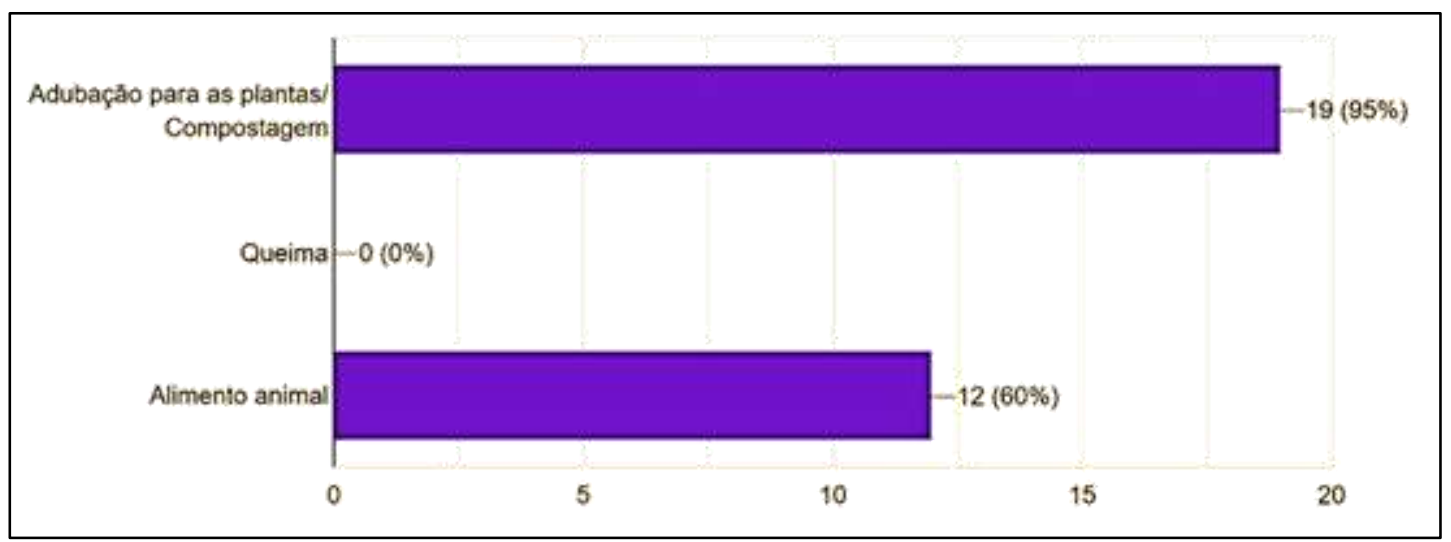

Fonte: Autores (2021).

Segundo a resolução do Conama $n^{\circ}$ 481, de outubro de 2017 (Conama, 2017), define-se compostagem como um processo de decomposição biológica controlada dos resíduos orgânicos, efetuado por uma população diversificada de organismos, em condições aeróbias e hemofílicas, resultando em material estabilizado, com propriedades e características 
completamente diferentes daqueles que lhe deram origem.

Os compostos orgânicos apresentam-se como uma matéria-prima alternativa para formulação de substratos. Segundo diversos autores, incluindo Marques (2016); Paiva, (2017) e Watthier et al., (2017) as características físicas e químicas apresentadas por substratos formulados a partir de compostos orgânicos podem ser consideradas adequadas para o desenvolvimento de mudas de diversas espécies.

De acordo com Do Nascimento et al. (2005), a utilização de Compostos orgânicos no solo proporciona muitos benefícios, como a melhora da qualidade do solo, favorecendo a retenção de água e a drenagem, além de melhorar sua aeração; redução da erosão, pois aumenta a capacidade de infiltração de água no solo; favorece a vida da macrofauna, devido a presença da matéria orgânica, acarretando na redução de incidências de doenças de plantas. Na comunidade, a grande maioria dos agricultores utilizam essa técnica como alternativa ao uso de fertilizantes sintéticos, esse fato pode justificar a não utilização de corretivos no solo como apresentado e discutido na figura 8. Por acreditarem que apenas a adubação orgânica pode propiciar o aumento da produtividade eles optam por sistemas mais biodinâmicos.

\subsection{Uso do fogo e conhecimento empírico sobre a atividade}

Sobre o uso do fogo na propriedade para limpeza da área $85 \%$ dos agricultores entrevistados informaram que não utilizam o fogo como técnica de limpeza, dado este informado na Figura 13. Os agricultores afirmam que a prática mais corriqueira utilizada é a de capina manual. Na pesquisa 10\% não quiseram se manifestar e 5\% utilizam o fogo para limpeza da área.

A prática do corte e queima é utilizada por questão de praticidade, economia de mão de obra e porque acreditam que dessa forma conseguem maiores produtividades por conta das cinzas deixadas nos solos.

Figura 13 - Uso do fogo na área de plantio.

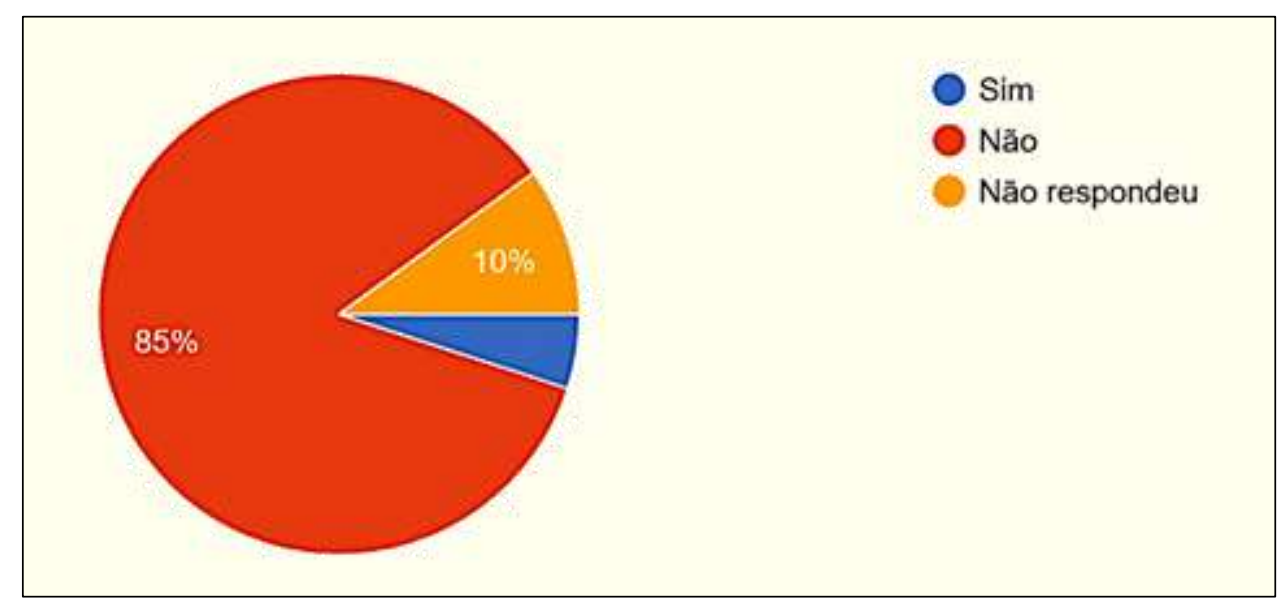

Fonte: Autores (2021).

Essa vocação para o uso do fogo na Amazônia remonta há séculos desde os primeiros paleoíndios que dominaram o seu uso. Com a entrada dos europeus, o uso do fogo decorreu da necessidade de limpar a área de forma mais barata, rápida e prática, além de proporcionar nutrientes, permitindo o seu cultivo, já sinalizado por Homma (2020) em seu capítulo de livro.

Segundo Leonel (2000), o autor argumenta que o uso descontrolado do fogo por todos os neobrasílicos, inclusive europeus, mestiços, caboclos, brancos e africanos, resultou nas plantations, que passaram a dominar a agricultura brasileira a partir da colonização, entre elas o algodão, a cana-de-açúcar, o café e, mais recentemente, a soja.

O que pôde ser observado, de forma discreta, foi que, os agricultores, apesar de utilizarem o fogo para limpeza de sua 
área não se sentiram à vontade em informar, acreditamos que por receio de que esta informação pudesse chegar aos órgãos públicos de fiscalização.

Imagens obtidas através do site "BDQueimadas - Programa Queimadas - INPE" que permite analisar focos de queimadas detectados por sistema de satélite de maneira temporal, demonstrou discordância quanto às respostas dos agricultores, confirmando a hipótese da informação prestadas pelos mesmos (Figura 14).

Figura 14 - Focos de queimadas na Comunidade São Sebastião do Livramento no período de 06/2019.

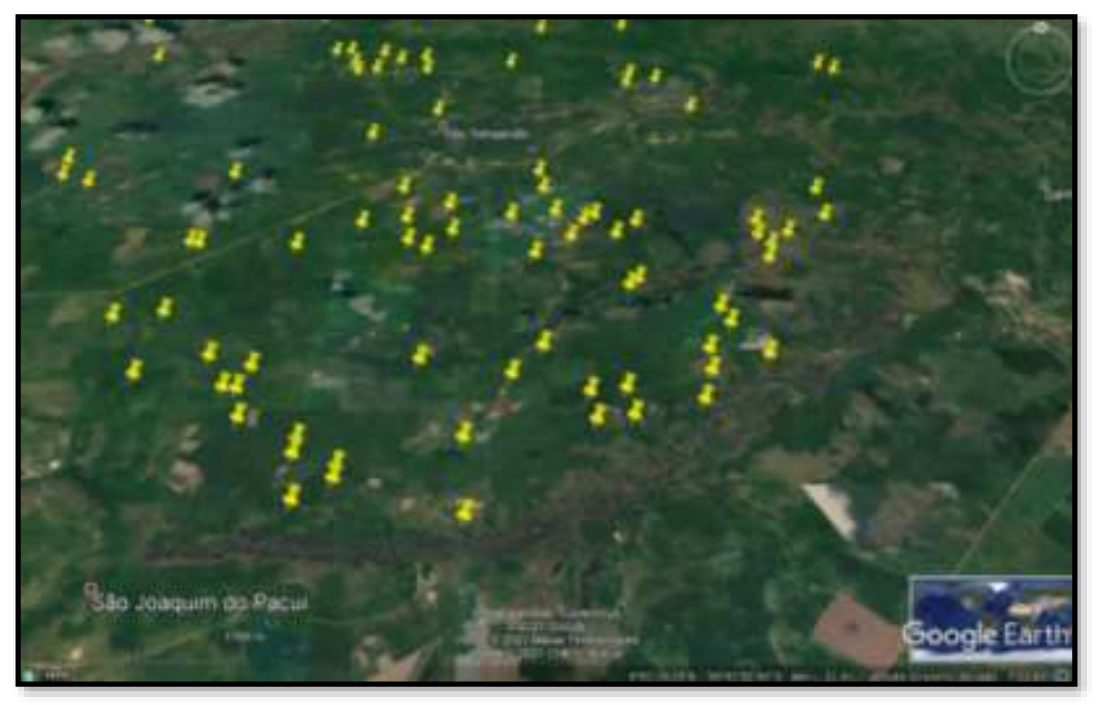

Fonte: INPE - DBQueimadas (2020).

Ao observar as imagens de satélite sobre os focos de queimadas na Comunidade concluímos que, no período de 2019, data da coleta das informações, ocorreram focos de queimadas, podendo ser ou não relativos às áreas dos agricultores.

Contudo, a imagem não confere com as respostas obtidas no questionário, deixando claro o receio em fornecer os dados. Os focos de queimadas, bem presente naquela região, confirmam que a atividade de corte e quiema pode estar passando por um processo de transição e ainda adotadas por agricultores.

Dados informados por Kato e Rego (2017), corroboram com a pesquisa quando afirmam que a agricultura de corte e queima é a forma de cultivo predominante nos estabelecimentos agrícolas familiares.

Outro levantamento temporal realizado na mesma região, contendo dados referente ao ano de 2020 apresentam a redução das queimas (ver Figura 15). Esta redução pode estar atrelada à diversos fatores como diminuição da área de plantio, acesso a tecnologias ou à sistemas alternativos técnica de derruba e queima. Agricultores que confirmaram que utilizam o fogo para limpeza da área também informaram estar passando por um processo de transição recebendo capacitações e vistas técnicas, mesmo que de forma insuficiente, por órgãos de extensão. Para eles, essas visitas, cursos, dias de campo, deveriam ser mais frequentes, pois estimularia e incentivaria a mudança de hábitos, visto que a atividade é vista como cultural e passado de geração à geração. 
Figura 15 - Foco por município de 06/2019 a 05/2020.

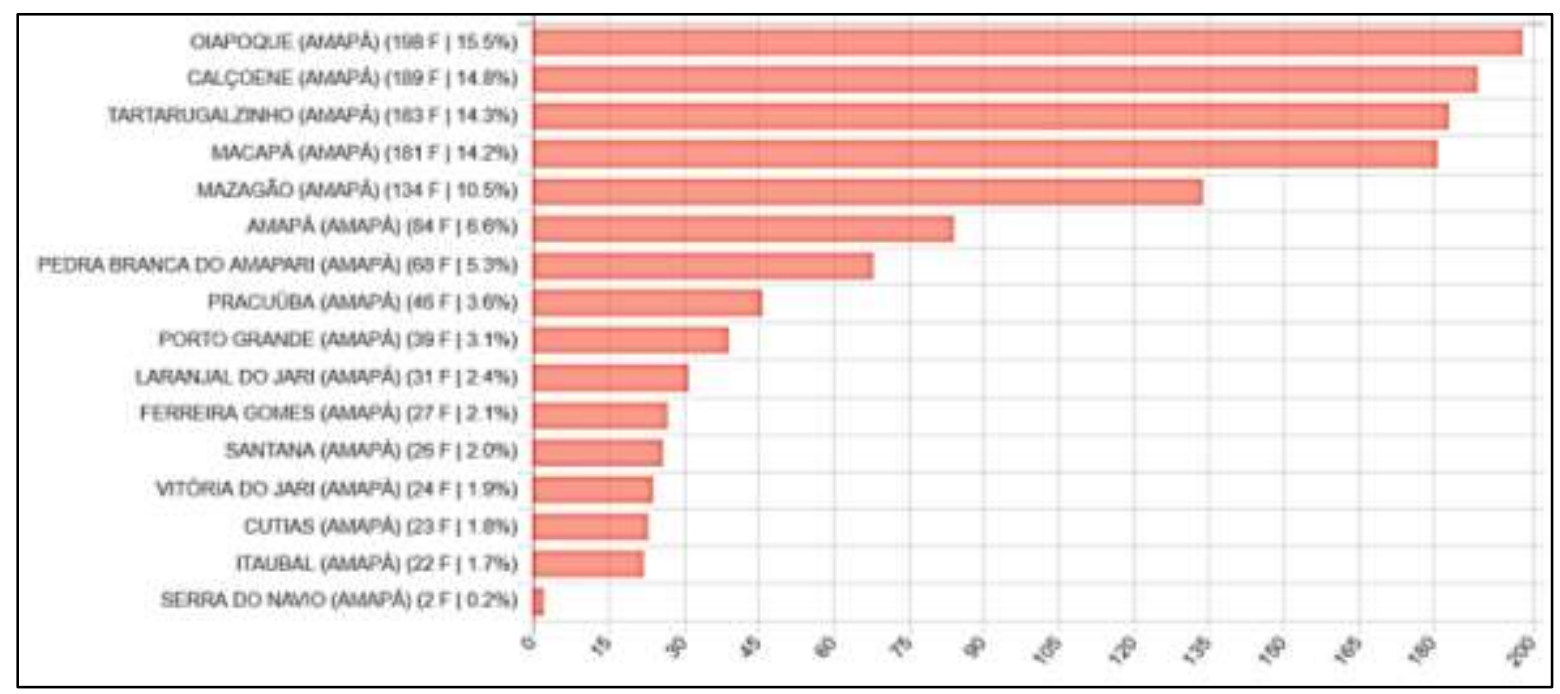

Fonte: INPE - DBQueimadas (2020)

A Figura 15 demonstra que o Município de Cutias, aonde está localizada a Comunidade da pesquisa, apresentou uma redução no índice de queimadas, podendo estar atrelado a fatores como conhecimento técnico, tecnologias, dentre outros citados anteriormente. Desta forma, essa questão requer maiores investigações.

Devemos considerar que estudos promissores quantos aos impactos negativos causados por essa prática vem sendo discutidos, dentre eles, a emissão de gases do efeito estufa e a redução na capacidade produtiva devido à diminuição no tempo de pousio, ocasionado pelo aumento populacional e pela necessidade de geração de alimentos e assim, novas formas de produção baseadas nos princípios da sustentabilidade vêm sendo apresentadas e aplicadas em sistemas agrícolas de produção familiar.

O próximo gráfico (Figura 16) discutirá as razões que levam os agricultores a decidirem sobre o uso do fogo na propriedade. Aqui eles afirmam que utilizam para reduzir os custos com a mecanização (85\%), despesa esta que onera a economia familiar. Outro fator sinalizado foi a falta de apoio institucional (10\%), mesmo sendo um quantitativo pequeno isso já demonstra a importância para eles da presença continuada de órgãos de extensão e assistência técnica. Outra razão apontada para o uso do fogo na propriedade foi para auxiliar na limpeza de restos culturais, como na queimada de resíduos do roçado, que para eles é uma atividade muito mais rápida e barato.

Figura 16 - Razões que levam ao uso do fogo na área de plantio.

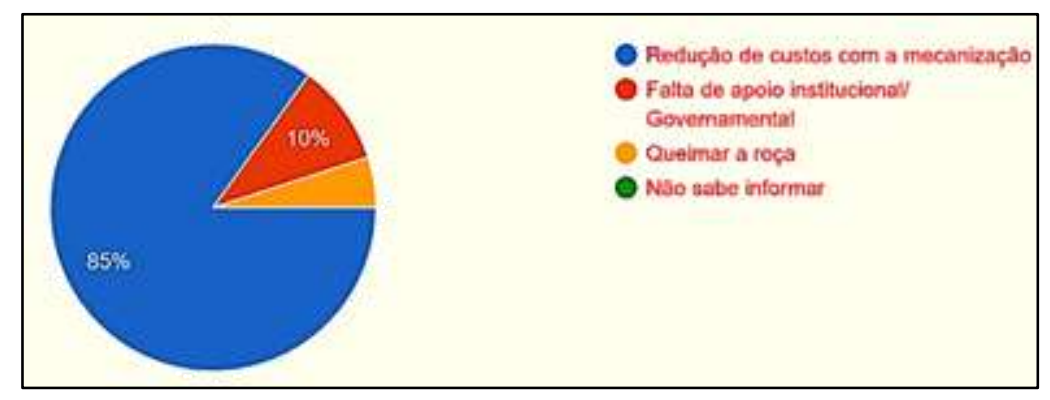

Fonte: Autores (2021).

De acordo com Costa e Lambertucci (2020), as mudanças no uso da terra na Amazônia brasileira, ainda no sistema de derruba e queima tem mídia global. Esse sistema é utilizado também na limpeza de áreas já desmatadas para novos cultivos e renovação de pastagens, independente da escala de produção. Fato este observado nesta pesquisa. Apesar do receio em confirmar 
o uso do fogo essa percepção pôde ser confirmada in loco e no levantamento de dados como o apresentado neste gráfico. Na sequência dados sobre a percepção dos agricultores quanto a vantagem do uso do fogo será apresentada.

Figura 17 - Vantagens do uso do fogo na área de plantio.

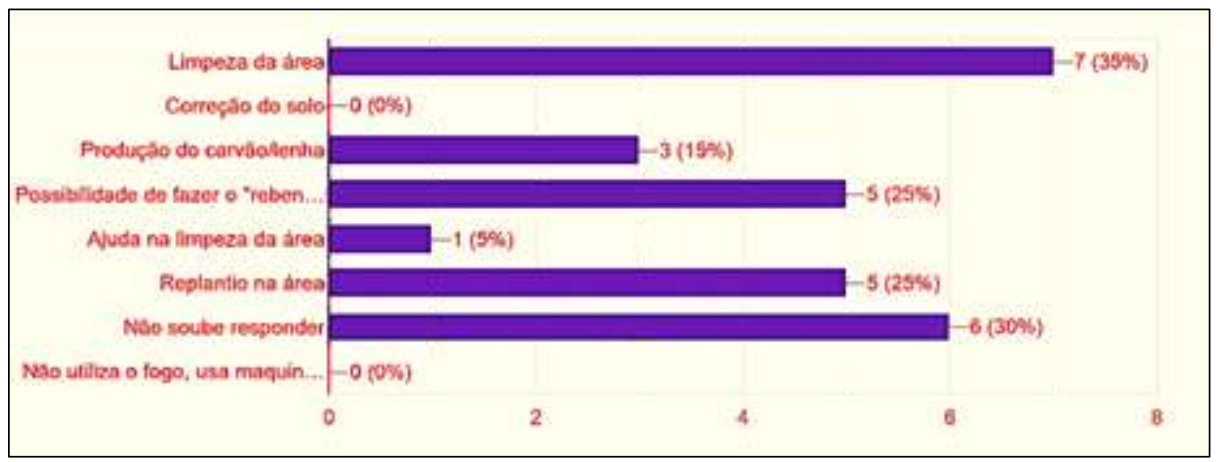

Fonte: Autores (2021).

Para 35\% dos agricultores o fogo auxilia no processo de limpeza da área de plantio. De acordo com relatos, como utilizam apenas a mão de obra familiar e o contrato para roçagem seria um valor agregado que financeiramente não compensaria e, ainda por ter pouco apoio de órgão públicos com o maquinário, então utilizar o fogo é uma saída mais econômica e rápida. Os serviços de assistência técnica e extensão rural são essenciais para o desenvolvimento sustentável da agricultura familiar, principalmente, no que se refere a inserção e viabilização de novas práticas agroecológicas.

As Figuras 18, 19 e 20 apresentam informações quanto ao conhecimento empírico dos agricultores sobre o resíduo das cinzas deixadas sobre o solo e suas vantagens para as plantas, para o solo e para a água. A pergunta foi direcionada no sentido de obter informações dos agricultores sobre conhecimentos mais específicos e técnicos e assim procurar compreender como eles realizam a sua dinâmica na escolha ou não do uso do fogo nas áreas de plantio. O que pôde-se perceber é que se trata de uma atividade realizada de cunho cultural, ou seja, passada por gerações e que, apesar das visitas técnicas e dos atendimentos por órgãos de extensão alguns ainda apresentam uma certa resistência em renunciar ao uso desta técnica e adotar medidas mais conservacionistas do uso do solo como a prática do plantio direto, uso de leguminosas, rotação de culturas, uso de pousio do solo, dentre outras.

Figuras 18 - Vantagens das cinzas deixadas pelo fogo para as plantas.

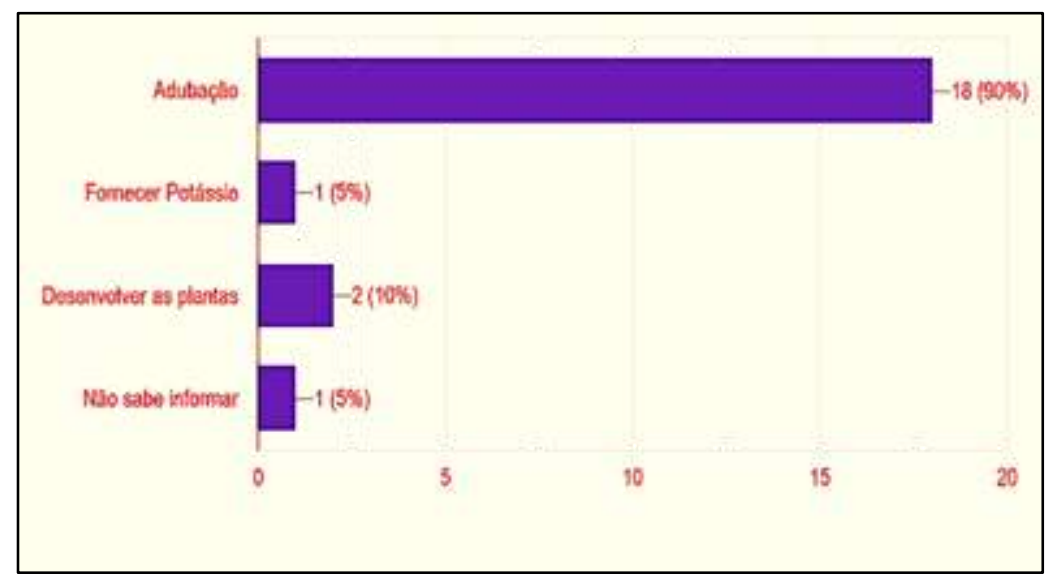

Fonte: Autores (2021). 
Figuras 19 - Vantagens das cinzas deixadas pelo fogo para o solo.

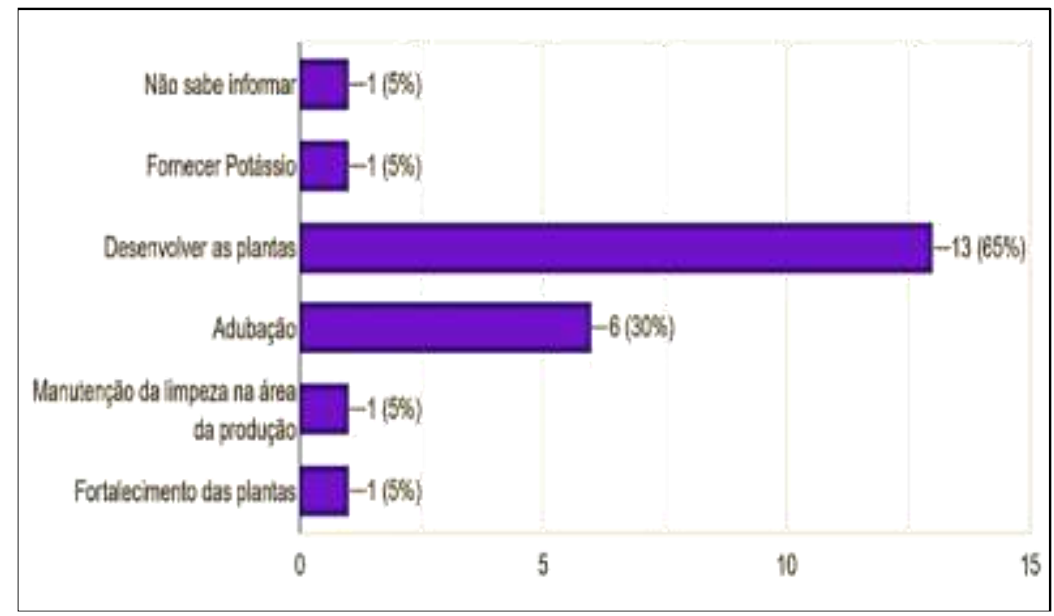

Fonte: Autores (2021).

Figuras 20 - Vantagens das cinzas deixadas pelo fogo para a água.

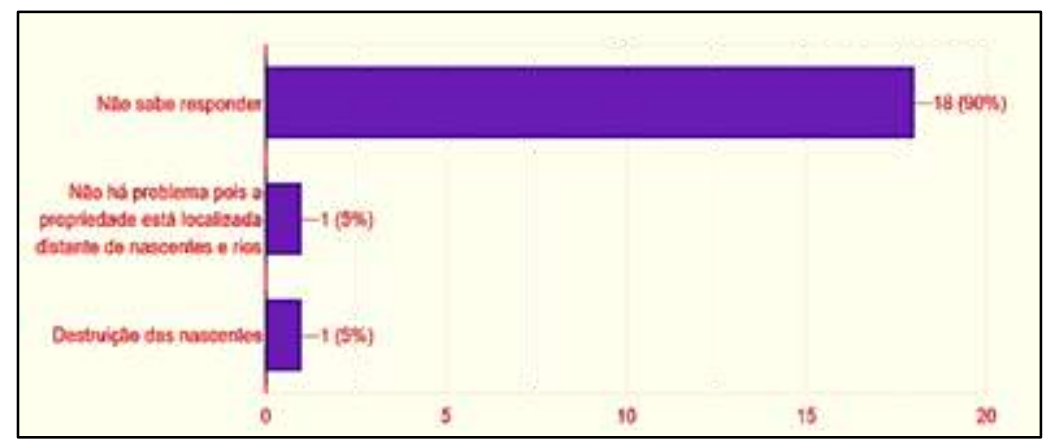

Fonte: Autores (2021).

De acordo com Bezerra (2013), as leis ambientais que visam à preservação do meio ambiente com ideias de reutilização dos resíduos gerados, a cinza resultante de queima de material vegetal tem sido vista como uma alternativa de corretivo de solo para a agricultura, pois contêm presença elevada de nutrientes como potássio, cálcio e magnésio necessários para a planta e para diminuir os níveis tóxicos de alumínio e manganês. Para grande parte dos agricultores, 65\% (Figura 19) deles acreditam que as cinzas atuam como adubo e funcionam para auxiliar no bom desenvolvimento das plantas, confirmando o que foi relatado pelo pesquisador supramencionado. Para os agricultores as cinzas despontam como um incremento mineral que completa a adubação e barateia os custos com a produção.

Estudos realizados por Osaki e Darolt (1991), Bonfim-Silva et al. (2011) e Spricigo et al., (2016) com as culturas da aveia, aveia preta e a rúcula, para os autores as cinzas melhoram a fertilidade dos solos, contribuem no desenvolvimento das plantas, dado este sinalizado por 90\% dos agricultores entrevistados podendo ser visto na Figura 18. Quanto ao resíduo das cinzas deixadas pelo fogo e sua implicação na água tanto para uso domético quanto para as plantas 90\% não sabem responder (Figura 20). Para Bonfim-Silva et al. (2011) as cinzas depositadas no solo apresentaram eficiência no uso da agua para as plantas, em seu experimento conforme ao aumento das doses de cinzas, em comparação a uma área não adubada, mais a eficiência do uso da água se aproximou de $95 \%$.

Apesar do uso do fogo também trazer benefícios, pesquisas mostram que as cinzas de queimadas provocam baixa oxigenação e aumento de pH nas águas subterrâneas. Dados recentes publicado por Oliveira -Filho (2020) afirmam que, não são só as águas superficiais atingidas pelas cinzas, mas contaminação de águas subterrâneas na área queimada é frequente. Os compostos nitrogenados, principalmente o nitrato, bem como os elementos potássio, fósforo, cálcio e magnésio, foram 
encontrados na água subterrânea em patamares acima dos normais, quando comparados a uma área controle. Essa elevação se manteve pelo período de doze meses após a ocorrência da queimada, quando finalmente retornou aos quantitativos iniciais.

Sobre o uso de fogo de forma controlada, 85\% dos agricultores (Figura 21) informaram que são detentores de conhecimento sobre a importância dos aceiros como uma técnica eficiente para dificultar com que o fogo se propague para outras áreas.

Figura 21 - Uso do fogo de forma controlada.

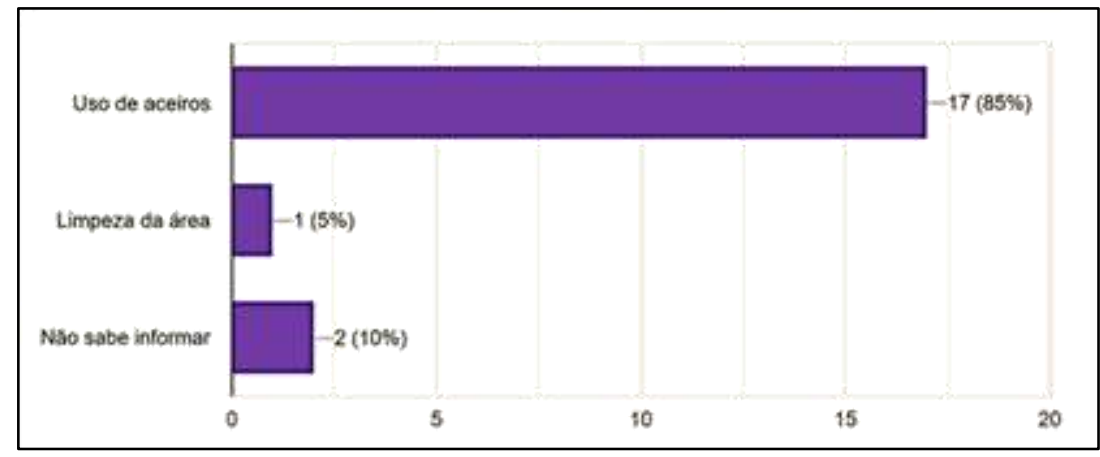

Fonte: Autores (2021).

Segundo Lorenzon et al., (2014), a queima controlada é uma técnica comum em ambiente rural para limpeza do terreno, renovação da vegetação e eliminação de pragas e doenças. Embora não seja a técnica mais adequada, por causa de alterações causadas no ambiente, ainda é a forma mais rápida e econômica que os produtores rurais possuem para atingir tais objetivos. Como relatado pelo agricultor S.M.A sobre o uso de aceiros: “(...) realizamos o aceiro com o auxílio de ferramentas, trator... fazemos uma raspagem na área da vegetação de forma que limite um aárea da outra evitando a passagem do fogo.” S.M.A. (2019).

No Brasil, a Portaria $\mathrm{n}^{\circ} 94$ - N de 1988 regulamenta o uso do fogo tecnicamente conhecido por queima controlada (Brasil, 1988). De acordo com Martins (2017), o fogo, enquanto queima controlada, é utilizado como uma técnica que deve ter um planejamento prévio, onde presumivelmente, os aspectos diretamente relacionados com seu comportamento deveram ser considerados, como o clima, material combustível e todas suas variações, a topografia, as técnicas de ignição, as ferramentas e equipamentos apropriados na sua aplicação, dentre outras.

Quanto ao conhecimento sobre a Legislação existente e vigente sobre o uso do fogo (Figura 22) 25\% dos agricultores informaram desconhecimento sobre o assunto, outros 10\% acreditam que a Legislação não "serve" para os pequenos agricultores e só beneficia o Agronegócio. Como, para eles, não há uma fiscalização mais intensa pelos órgãos competentes $15 \%$ acreditam ser este o motivo que contribui para que a técnica da queima ainda seja priorizada e praticada pelos agricultores, assim $15 \%$ dos entrevistados relataram que se houver fiscalização quanto ao atendimento da Legislação reduziria a aplicação de multas (10\%). 
Figura 22 - Conhecimento sobre a Legislação do uso do fogo.

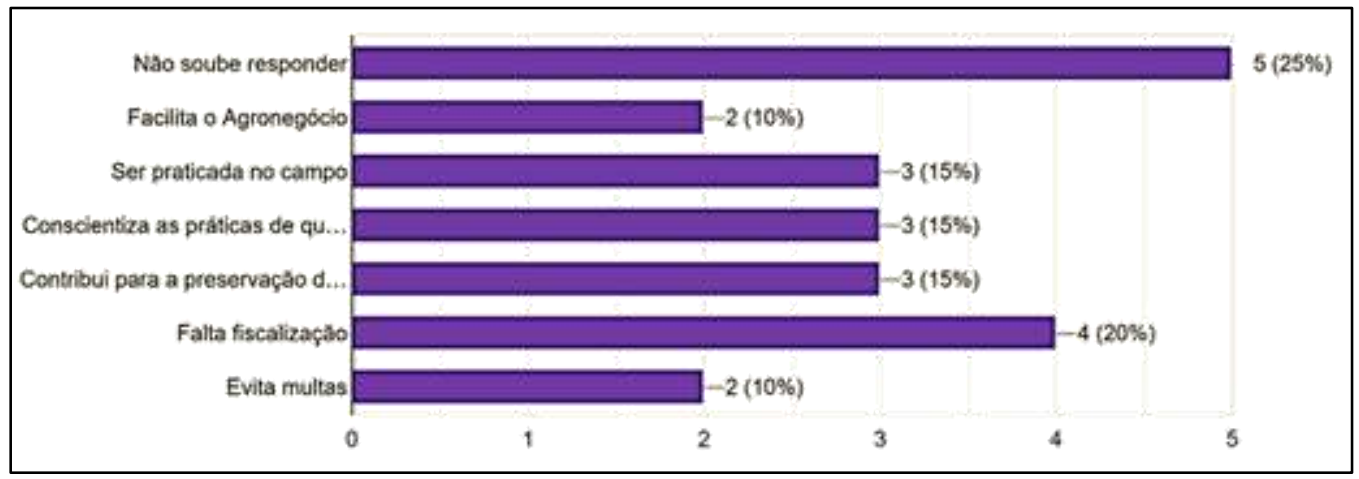

Fonte: Autores (2021).

Segundo Martins (2017) a legislação prevê o uso do fogo de forma racional a minimizar seus efeitos maléficos, otimizando os benefícios. $\mathrm{O}$ fogo como qualquer outra técnica não deve ser empregado em todas as situações, sendo necessário conhecer o histórico da área a ser manejada. Ainda quando tratamos sobre legislação do uso do fogo não devemos de fazer menção a Lei no 12.651, de 25 de maio de 2012, traz novas considerações sobre o uso do fogo em forma de queima controlada. Os Incisos I e II do Artigo $38^{\circ}$ "preveem o emprego do fogo em locais ou regiões cujas peculiaridades justifiquem seu emprego em práticas agropastoris ou florestais, assim como em Unidades de Conservação e ainda em atividades de pesquisa científica vinculada a projeto de pesquisa devidamente aprovado pelos órgãos competentes e realizada por instituição de pesquisa reconhecida" (Brasil, 2012).

Para utilizar as queimadas controladas o agricultor necessita ter conhecimento que há um órgão regulatório para tal atividade, no Brasil o Sistema Nacional do Meio Ambiente (SISNAMA) é a quem compete a autorização, assim o agricultor deve considerar: o uso de aceiros ( $3 \mathrm{~m}$ mínimo), uso de equipamentos de proteção, mão de obra qualificada, observas a distância entre as Áreas de Reserva Legal e de Proteção Permanente, caracterizar a área, tipo de vegetação presente, dentre outras medidas prescritas pelo órgão competente, bem como informar aos órgãos fiscalizadores oficiais do estado e/ou município. Tais medidas são importantes para que se possa evitar o uso indiscriminado do fogo.

Manejar o fogo de maneira consciente é possível, desde que sejam adotadas técnicas que considerem a legislação vigente, aprimorando técnicas e práticas sugeridas por órgãos de pesquisa compatível com as potencialidades locais.

\subsection{Desvantagens do uso do fogo pelos agricultores}

O uso do fogo na agricultura ainda é uma técnica que persiste nacionalmente, embora os avanços nas tecnologias alternativas ao uso do fogo estejam ocorrendo, o uso do fogo ainda apresenta melhorias significativas no sistema produtivo mesmo que nos primeiros anos de plantio. Mesmo assim, desvantagem deve ser sinalizadas e apontadas como aspectos importantes para a condução e melhoria em sistemas produtivos e melhorias ambientais.

No levantamento das informações sobre o conhecimento dos agricultores sobre as desvantagens ocorridas quanto ao uso do fogo (Figura 23), 45\% a 55\% dos agricultores acreditam que o fogo contribui para a poluição atmosférica, 10\% destroem as nascentes e 5\% dos agricultores afirmam ter conhecimento de que uma das desvantagens é a diminuição da biota que existe no solo. 
Figura 23 - Desvantagem ao uso do fogo pelos agricultores.

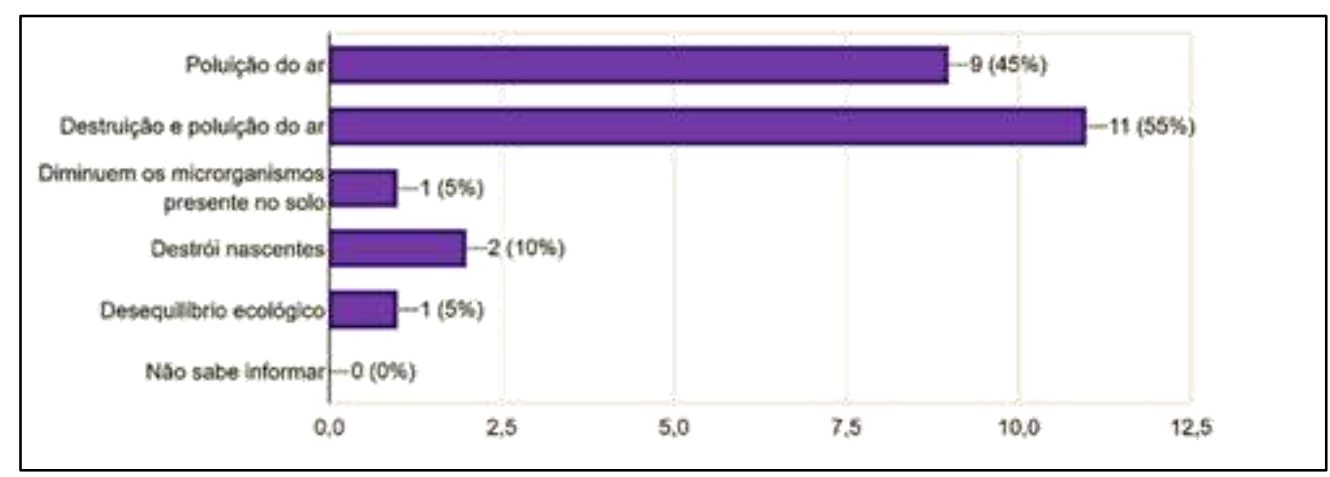

Fonte: Autores (2021).

Fontoura e Verdum (2010) informam que a modernização das técnicas de produção acarretou mudanças nos sistemas produtivos agrícolas, sociais e econômicos, estes modelos despontam como uma forma de reduzir a degradação oriundas de práticas de manejo inadequado.

Rodrigues et al. (2016) encontrou resultados similares ao desta pesquisa, onde agricultores apontaram que os problemas e desvantegens encontradas no uso dessa técnica está atrelada ao uso da poluição das águas, das nascentes, destruição da flora e da fauna. Para esses agricultores o que falta é uma fiscalização e treinamentos quanto a técnica de manejo ecologico dos solos. É de conhecimento que, a queimada altera, direta ou indiretamente, as características físicas, químicas, morfológicas e biológicas dos solos, como o pH, teor de nutrientes e carbono, biodiversidade da micro, meso e macrofauna, temperatura, porosidade e densidade. Sem falar no aumento do efeito estufa, na redução da qualidade do ar e da água, e da saúde (Capeche, 2012).

Assim, a transferência de tecnologia e a educação ambiental são fundamentais para a adoção das práticas conservacionistas e evitar queimadas.

Quanto aos seus conhecimentos sobre os cuidados utilizados quando decidem utilizar o fogo (Figura 24) ou ainda se não utilizam quais os seus conhecimentos sobre o assunto $40 \%$ não souberam responder o que fazer, ou seja, fica claro o desconhecimento sobre as medidas a serem tomadas. 35\% afirmam que os cuidados utilizados é quanto a observação do horário para o estabelecimento das queimadas, outros cuidados como o uso de aceiros e os contraventos também foram medidas sinalizadas que podem ser adotadas como um dos cuidados estabelecidos para o uso do fogo.

Figura 24 - Cuidados que devem ser tomados na utilização do fogo.

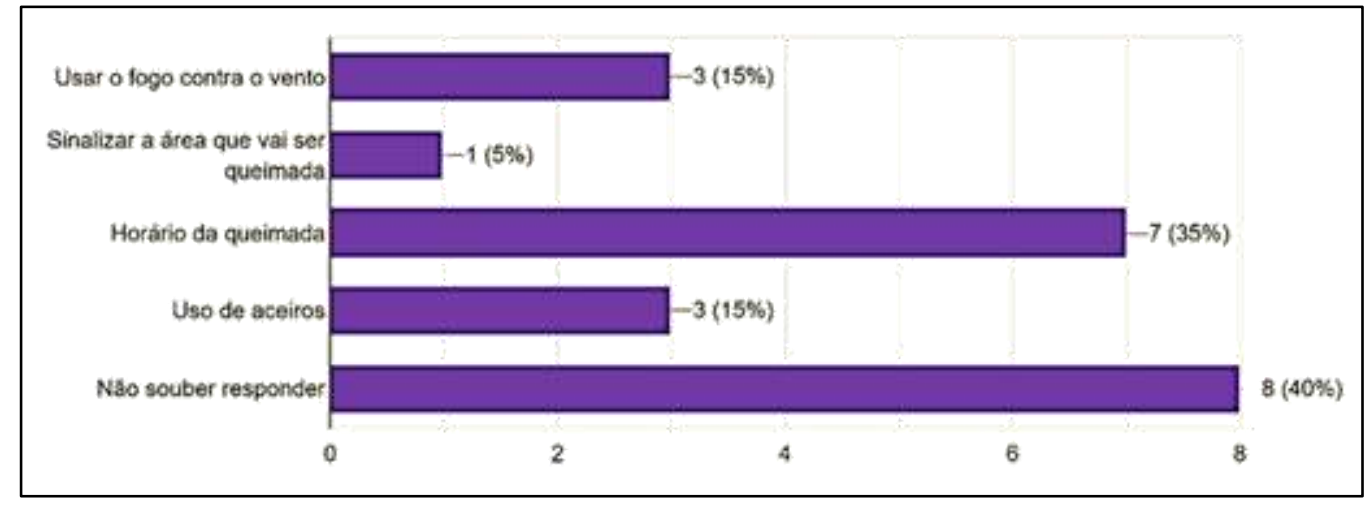

Fonte: Autores (2021).

Em trabalho desenvolvido por Santos (2018), com resultados semelhantes ao obtido nessa pesquisa os mesmo informam sobre o uso do aceiro, orientações com brigadistas, controlar o horário das queimadas. 
Outros cuidados e precauções citados por Rodrigues (2016) sobre o uso do fogo é que essa atividade não deve realizada sozinha, de acordo com os seus levantamentos de dados os agricultores informaram que essa prática deve ser iniciada por mais de uma pessoa, cuidado com a morte dos animais, cuidado com as queimadas em áreas de reserva, destruição de fontes hídricas. Constatou-se nesta pesquisa e nas fontes de dados analisadas que os agricultores apresentam uma preocupação quanto a utilização do uso do fogo, bem como é de conhecimento deles os perigos causados por ele.

Faz-se necessário que medidas mitigadoras para viabilizar alternativas mais ecológicas e práticas conservacionistas sejam adotadas.

\section{Conclusão}

Os dados levantados neste trabalho são de fundamental importância para que tanto os agricultores quanto os gestores e órãos de fiscalização possam pensar em medidas que poderão ser adotadas para auxiliar nas técnicas de uso e conservação dos solos.

A opção pelo uso do fogo na Comunidade está intimamente relacionada com os aspéctos de redução de custos (economicidade), praticidade e agilidade na limpeza da área de produção. A cultura da mandioca desponta como uma das principais culturas utilizada nos roçados $(95 \%)$ e a prática do corte, queima e destoca foi sinalizada por alguns agricultores como prática culturalmente realizada.

A maior parte dos entrevistados, $85 \%$ dos agricultores, informaram que não utilizam o fogo como técnica de limpeza, contudo dados estes que divergem das informações obtidas através da imagem de satélite. Acreditamos que os agricultores não se sentiram confortáveis em informar por receio de que esta informação pudesse chegar aos órgãos públicos de fiscalização.

Grande parte dos agricultores (90\%) conhecem as vantagens das cinzas deixadas pelo uso do fogo para as plantas e alguns (45\%) sabem de sua importância para o solo. Quanto a desvantagem do uso do fogo (55\%) dizem ter conhecimento, contudo observou-se, de acordo com os dados apresentados (25\%) que desconhecem a Legislação.

Técnicas singulares para evitar desmatamentos e queimadas como a utilização contínua da mesma área mediante destoca, aração e gradagem, além de cuidados como a conservação de solos, efetuando rotação de cultivos com leguminosas, plantio direto e variedades mais produtivas, foram também apontadas como utilizadas pelos agricultores necessitando, contudo, serem mais incentivadas e estarem disponíveis e viáveis economicamente para os agricultores.

É necessário que políticas públicas sejam implementadas, objetivando reduzir o custo de recuperação, que no momento é bastante elevado e induz a utilização de práticas não sustentáveis mais baratas.

\section{Referências}

Almeida, E., Sabogal, C. \& Brienza Júnior, S. (2006). Recuperação de Áreas Alteradas na Amazônia Brasileira: Experiências Locais, Lições Aprendidas e Implicações para Políticas Públicas. Belém, Cifor. http://www.alice.cnptia.embrapa.br/alice/handle/doc/375969.

Almeida, L. N. (2019). Queimadas agrícolas geram danos ao solo e à produção. Ministério da Agricultura Pecuária e Abastecimento - MAPA. Tribuna do Norte. www.tribunadonorte.com.br/noticia/queimadas-agricicolas-geram-danos.

Alves, R. N., Junior, M., \& Souza, M. d. (2013). Roça sem fogo planejamento da mandioca. Revista e Cidadania \& Meio Ambiente.

Balsan, R. (2006). Impactos decorrentes da modernização da agricultura brasileira. CAMPO-TERRITÓRIO, Revista de geografia Agrária, 1(2), 123-151. http://www.seer.ufu.br/index.php/campoterritorio/article/view/11787.

Bardin, L. (2009). Análise de Conteúdo. Editora 70.

Bervald, C. M. P., Kato, O. R., \& Reichert, J. M. (2011). Agregados a seco e compressibilidade de Latossolo Amarelo submetido a preparos tradicionais e alternativo na Amazônia Oriental. (1), 3-6.

Bezerra, M. D. L. (2013). Cinza vegetal como corretivo e fertilizante no cultivo de capim-marandu em solos do cerrado Mato-Grossense. Dissertação (Mestrado) - Universidade Federal de Mato Grosso, Instituto de ciências agrárias e tecnológicas, programas de Pós-graduação em Engenharia Agrícola, Rondonópolis MT. http://ri.ufmt.br/handle/1/1106. 
Brasil, (1998). Decreto n 2.661 de 8 de julho de 1998. Uso do Fogo. BRASIL. Portaria no $94-\mathrm{N}$ de 9 de julho de 1998 e publicada no Diário Oficial da União de 31 de julho de 1998. Regulamenta a Queima Controlada.

Brasil, (2010). Lei n. ${ }^{\circ}$ 12.305, de 2 de Agosto de 2010. Institui a Política Nacional de Resíduos Sólidos; altera a Lei n 9.605, de 12 de fevereiro de 1998; e dá outras providências. Diário Oficial da União, Brasília, DF.

Brasil, (2011). Brasília: Ministério da Saúde. Portaria no 2914 de 12 de dezembro de 2011.

Brasil, (2019). Decreto Federal n 12.651 de 25 de maio de 2012. Institui o Novo Código Florestal Brasileiro. Brasília, DF, 2012. http://www.planalto.gov.br

Brasil. Decreto Federal no 23.793 de janeiro de 1934. Decreta o Código Florestal. Brasília, DF, 1934. http://www.planalto.gov.br

Bonfim-Silva, E. M., Silva, T. J. A., Santos, C. C., Cabral, C. E. A. \& Santos, I. B. (2011). Características produtivas e eficiência no uso de água em rúcula adubada com cinza vegetal. Enciclopédia Biosfera, Centro Científico Conhecer-Goiânia, ISSN 2317-2606, 7(13).

Cabral, A. L. A., Filho, L. O. M. \& Borges, L. A. C. (2013). Uso do fogo na agricultura: Legislação, impactos ambientais e realidade na Amazônia. IX Fórum Ambiental da Alta Paulista, 9(5), 159-172. https://doi.org/10.17271/19800827952013577.

Capeche, C. L. (2012). Impactos das queimadas na qualidade do solo - degradação ambiental e manejo e conservação do solo e água. In.: Anais do II Encontro Científico do Parque Estadual dos Três Picos. http://www.alice.cnptia.embrapa.br/alice/handle/doc/956695.

Ceretta, G. F., Silva, F. K. \& Rocha, A. C. (2013). Gestão ambiental e a problemática dos resíduos sólidos domésticos na área rural do município de São JoãoPR. Revista ADMpg Gestão estratégica (Online), 6(1), 17-25. http://www.admpg.com.br/revista2013_1/Artigos/08\%20Gestao\%20Ambiental\%20e\% 20a\%20problematica\%20dos\%20residuos.pdf

Cravo, M. da S., Corteletti, J., Nogueira, O. L., Smyth, T. J. \& Souza, B. D. L. de. (2005). Sistema Bragantino: Agricultura Sustentável para a Amazônia. Belém, Embrapa Amazônia Oriental.

Coelho, E. F., Silva, A. J. P., Silva, T. S. M. \& Parizotto, I. (2015). Sistemas de irrigação em agricultura familiar: eficiência e potencialidade de adoção. In: III Inovagri International Meeting. http://www.alice.cnptia.embrapa.br/alice/handle/doc/1025531.

Costa, R. A. K. \& Kato, O. R. (2017). Agricultura de corte e queima e alternativas agroecológicas na Amazônia. Novos Cadernos NAEA, 20(3), $203-224$.

Denich, M., Vlek, P. L. G., Sá, T. D. de A., Vielhauer, K. \& Lücke, W. (2005). A Concept for the Development of Fire-free Fallow Management in the Eastern Amazon, In.: Brazil. Agriculture Ecosystems \& Environment, 110, 43-58. https://doi.org/10.1016/j.agee.2005.05.005.

Evangelista, E. (2021). Alternativas ao uso do fogo na agricultura e as etapas para planejamento de uma queimada controlada. http://www.embrapa.br/busca-denoticias/-/noticia/2471085/alternativas-ao-uso-do-fogo-na-agricultura-e-as-etapas-para-planejamento-de-uma-queimada-controlada.

Fontoura, L. F. M. \& Verdum, R. (2010). Questão agrária e legislação ambiental. UFRGS.

Gomes, J. C. \& Leal, E. C. (2003). Cultivo da mandioca para a região dos Tabuleiros Costeiros. Embrapa Mandioca e Fruticultura, Sistemas de Produção ISSN 1678-8796, 11 .

Homma, A. K. O. (2020). Amazônia: a civilização do fogo. In.: n: Alves, R. N. B., Modesto Junior, M. de S. (Ed.). Roça sem fogo: da tradição das queimadas à agricultura sustentável a Amazônia. Embrapa.

IBGE. (2006). Censo agropecuário: agricultura familiar 2006. http://www.ibge.gov.br/home/presidencia/noticias/noticia_visualiza.php?id_noticia=1466\&id_p agina $=1>$.

Icmbio - Instituto Chico Mendes de Conservação da Biodiversidade. (2010). Manual para Formação de Brigadista de Prevenção e Combate aos Incêndios Florestais. ICMBIO e Ministério do Meio Ambiente. Brasília. https://www.icmbio.gov.br/portal/images/stories/servicos/sejaumbrigadista.pdf

Rurap-Instituto de Desenvolvimento Rural do Amapá. (2015). Relatório de atividades. RURAP.

Kato, O. R., Kato, M. do S., Sá, T. de A. \& Figueiredo, R. (2004). Plantio Direto na Capoeira. In.: Ciência \& Ambiente, 29, 99-111. http://www.alice.cnptia. embrapa .br/alice/h andle/doc/408529.

Kazubek, M. (2010). O problema do lixo rural. Jornal Hoje Centro Sul, 1, 1. https://hojecentrosul.com.br/colunas/o-problema-do-lixo-rural/.

Lemos, A. L. F, Vital, M. H. F, \& Pinto, M. A. C. (2010). As Florestas e o painel de mudanças climáticas da ONU. BNDES Setorial, 32, 153-192. http://web.bndes.gov.br/bib/jspui/handle/1408/2023.

Leonel, M. (2000). O uso do fogo: o manejo indígena e a piromania da monocultura. Estudos Avançados, 14(40), 231-250. https://doi.org/10.1590/S010340142000000300019

Lorenzon, A. S., Brianezi, D., Valdetaro, E. B., Souza, C. M., Martins, S. V., Ribeiro, C. A. A. S., Silva E. \& Jacovine,L. A. G. (2014). Análise química de um solo florestal após ocorrência de fogo. Revista Brasileira de Agropecuária Sustentável - Brazilian Journal of sustainable agriculture. 4(2). https://doi.org/10.21206/rbas.v4i2.269.

Machado, D. da S. L. MAPA. (2019). Laboratório de Ecossistemas/LABECO. Universidade do Estado do Amapá.

Martins, M. C. (2017). Fogo: visões, possibilidades e limites do seu uso na agricultura, nas unidades de conservação e nas atividades florestais. Universidade Federal de Viçosa, Tese apresentada para otenção do (Título Doctor Scientiae). Viçosa, MG. http://www.locus.ufv.br/handle/123456789/11549.

Matos, F. F. de, Martins, P. F. da S. \& Silva, L. M. S. (2019). Assimilação de inovações técnicas de Cultivo sem queima em sistema de produção familiar na periferia da Amazônia Oriental. Associação Brasileira de Agroecologia, 14(1), 33-39. 
Melém Júnior et al., (2008). Análise de componentes principais para avaliação de resultados analíticos da fertilidade de solos do Amapá. Semina: Ciências Agrárias, 29(3), 499-506. http://www.alice.cnptia.embrapa.br/alice/handle/doc/353064.

Nepstad, D. C., Moreira, A. G. \& Alencar, A. A. (1999). Florestas em chama: Origens, Impactos e Prevenção do fogo na Amazônia. In: IPAM. Programa Piloto para Proteção das Florestas Tropicais do Brasil. IPAM: Brasília.

Oliveira-Filho, E. C. (2020). Efeitos das cinzas das queimadas sobre os ecossistemas aquáticos. EcoDebate.

Osaki, F. \& Darolt, M. R. (1991). Estudo da qualidade de cinzas vegetais para uso como adubos na região metropolitana de Curitiba. Revista Setor Ciências Agrárias, Guarapuava, 11(1).

Pires, W. (2020). Roçadas ou herbicidas: qual o jeito certo de controlar plantas daninhas. http// https://www.girodoboi.com.br/noticias/rocadas-ou-herbicidasqual-o-jeito-certo-de-controlar-plantas-daninhas/

Pontes, F. (2016). Amazônia Real. In: http:// amazoiareal.com.br/.

Queiroz, K. B. (2016). Qualidade físico-química da água para irrigação ao meio a escassez no Maciço De Baturité-CE. Mostra Científica em Biomedicina, Baturité-CE, 1(1), 1-4.

Ramos, P. C. M. (2004). Manual de operações de prevenção e combate aos incêndios florestais: comportamento do fogo. IBAMA, 60.

Richetti, A. (2007). Custo de produção de mandioca industrial, safra 2007. Revista Raízes e Amidos Tropicais, 3(1).

Rocha, A. C., Ceretta, G. F., Botton, J. S., Baruffi, L. \& Zamberlan, J. F. (2013). Gestão de resíduos sólidos domésticos na zona rural: a realidade do município de Pranchita - PR. Revista de Administração da UFSM, 5, 699-714. https://doi.org/10.5902/198346597657.

Rodrigues, M. F., Rocha, F. E. de C., Corte, J. L. D., Salviati, M. E. V., O-F. \& Cyrino, E. (2016). Aspectos motivacionais para o uso do fogo na agricultura no Distrito Federal e entorno. Boletim de Pesquisa e Desenvolvimento/Embrapa Cerrados.

Santos, J. A. C. (2018). Uso do fogo na agricultura: medidas preventivas e queimada controlada no projeto de desenvolvimento sustentável terra nossa, Novo Progresso, Pará. Revista Agroecossistemas, 10(2), 353-366. https://doi.org/10.18542/ragros.v10i2.5211.

Sá, T. de A. de A., Kato, O. R., Carvalho, C. J. R. de, \& Figueiredo, R. de O. (2007). Queimar ou não queimar? De como produzir na Amazônia sem queimar. REVISTA USP, São Paulo, (72), 90-97. https://doi.org/10.11606/issn.2316-9036.v0i72p90-97.

Salais, R. (1996). Dynamiques territoriales et mutations économiques. Paris: 1’Harmattan, Préface. In: Pecqueur, B. (Ed.).

Sandri, D. \& Rosa, R. R. B. (2017). Atributos químicos do solo irrigado com efluente de esgoto tratado, fertirrigação convencional e água de poço. IRRIGA Brazilian Journal of Irrigation and Drainage, Botucatu, 22(1), 18-33. https://doi.org/10.15809/irriga.2017v22n1p18-33.

Silva, F., Rodrigues, da S. J. Y. \& Palheta da S. L. (2014). Efeito do desmatamento e do programa de transferência de renda Bolsa Família na produção da mandioca (Manihot esculenta Crantz) no estado do Pará, en Observatorio de la Economia Latinoamericana, (197). http://www.eumed.net/cursecon/ecolat/br/14/produzao-mandioca.hmtl.

Silva, M. M. da, Lovato, P. E., \& Vieira, I. C. (2006). Projeto roça sem queimar: uma proposta de manejo agroecológico para a região da transamazônica PARÁ. Cadernos de Agroecologia, 1(1).

Spricigo, J. G., Chagas, A., Naibo, G., Delazeri, P., Pedó, R. \& Alves, M. V. (2016). Efeito de diferentes doses de cinza no desenvolvimento da aveia preta. In: SIEPE, Ciência, tecnologia e inovação, 9, Seminario de Iniciação Cientifica, 22., Curitiba. https://portalperiodicos.unoesc.edu.br/siepe/article/view/10984.

Testezlaf, R. (2011). Irrigação: métodos, sistemas e aplicações. Unicamp/FEAGRI. http://bibspi.planejamento.gov.br/handle/iditem/451.

Tourrand, J. F., \& Veiga, J. B. da. (2003). Viabilidade de Sistemas Agropecuários na Agricultura Familiar da Amazônia. Belém, Embrapa Amazônia Oriental.

Venturieri et al. (2017). Mapeamento de solos e aptidão agrícola das terras do Cerrado Amapaense, realizado em escala de reconhecimento de alta intensidade, como subsídio ao MacroZEE._ Belém, PA : Embrapa Amazônia Orienta, $48 . \quad$ (Documentos/Embrapa Amazônia Oriental,). http://www.infoteca.cnptia.embrapa.br/infoteca/handle/doc/1073439.

Wadt, L. H.; Valentin, J. F.; \& Pereira, J. B. M. (2006). Uso do fogo na agricultura Acre. Revista Agronline.

World Wildlife Fund. (2019). Solucionar a poluição plástica: transparência e responsabilização. ISBN 978-2-940529-93-3, Relatório WWF 2019 por Dalberg, [s. 1.]. 